\title{
Thermodynamic Control on the Poleward Shift of the Extratropical Jet in Climate Change Simulations: The Role of Rising High Clouds and Their Radiative Effects
}

\author{
YING LI AND DAVID W. J. THOMPSON \\ Department of Atmospheric Science, Colorado State University, Fort Collins, Colorado \\ SANDRINE BONY \\ Laboratoire de Météorologie Dynamique, IPSL, CNRS, Université Pierre et Marie Curie, Paris, France \\ TIMOTHY M. MERLIS \\ Department of Atmospheric and Oceanic Sciences, McGill University, Montreal, Quebec, Canada
}

(Manuscript received 27 June 2018, in final form 24 October 2018)

\begin{abstract}
Extratropical eddy-driven jets are predicted to shift poleward in a warmer climate. Recent studies have suggested that cloud radiative effects (CRE) may enhance the amplitude of such shifts. But there is still considerable uncertainty about the underlying mechanisms, whereby CRE govern the jet response to climate change. This study provides new insights into the role of CRE in the jet response to climate change by exploiting the output from six global warming simulations run with and without atmospheric CRE (ACRE). Consistent with previous studies, it is found that the magnitude of the jet shift under climate change is substantially increased in simulations run with ACRE. It is hypothesized that ACRE enhance the jet response to climate change by increasing the upper-tropospheric baroclinicity due to the radiative effects of rising high clouds. The lifting of the tropopause and high clouds in response to surface warming arises from the thermodynamic constraints placed on water vapor concentrations. Hence, the influence of ACRE on the jet shift in climate change simulations may be viewed as an additional "robust" thermodynamic constraint placed on climate change by the Clausius-Clapeyron relation. The hypothesis is tested in simulations run with an idealized dry GCM, in which the model is perturbed with a thermal forcing that resembles the ACRE response to surface warming. It is demonstrated that 1) the enhanced jet shifts found in climate change simulations run with ACRE are consistent with the atmospheric response to the radiative warming associated with rising high clouds, and 2) the amplitude of the jet shift scales linearly with the amplitude of the ACRE forcing.
\end{abstract}

\section{Introduction}

Climate models predict a robust poleward shift of the extratropical eddy-driven jet and its associated storm track in response to increased greenhouse gases, particularly in the Southern Hemisphere (SH; e.g., Hall et al. 1994; Kushner et al. 2001; Yin 2005; Barnes and Polvani 2013; Vallis et al. 2015). Such shifts are thought to arise in response to changes in the meridional and vertical gradients in atmospheric temperature under climate change and their interactions with waves and wave breaking (e.g., Polvani and Kushner 2002; Lorenz and DeWeaver 2007; Chen and Held 2007; Butler et al. 2010; Lorenz 2014; Frierson 2008). However, the magnitude of the jet response

\footnotetext{
Corresponding author: Ying Li, ying.li@colostate.edu
}

to climate change shows considerable spread across phase 5 of the Coupled Model Intercomparison Project (CMIP5) models (Taylor et al. 2012; Barnes and Polvani 2013; Voigt and Shaw 2016).

The spread in the jet response to increasing carbon dioxide $\left(\mathrm{CO}_{2}\right)$ has been traced back to cloud radiative effects in numerous previous papers (e.g., Ceppi et al. 2012, 2014; Voigt and Shaw 2015, 2016; Ceppi and Hartmann 2016; Ceppi and Shepherd 2017). Ceppi and Hartmann (2016) and Ceppi and Shepherd (2017) suggest that more than half of the total jet shift is caused by the radiative heating due to cloud changes in simulations using cloud-locking techniques run with interactive SSTs. In these cloud-locking experiments, the circulation response to climate change can be decomposed into 1) contributions from cloud changes while holding $\mathrm{CO}_{2}$ fixed, and 2) contributions from $\mathrm{CO}_{2}$ 
changes while holding the clouds fixed. Ceppi and Hartmann (2016) found, in an atmospheric model coupled to a slab aquaplanet ocean, that the influence of shortwave (SW) cloud radiative changes on SST and surface baroclinicity are central in governing the amplitude of the atmospheric circulation response. In their analysis, the longwave (LW) cloud radiative changes at the upper level oppose those at the lower level, and thus have no effect on the jet shift. Their results support their earlier findings that the intermodel spread in SW cloud radiative effects and their attendant effects on SSTs are responsible for the intermodel spread in the jet response to global warming (Ceppi et al. 2012, 2014).

However, even in the absence of coupling to the SST field and thus in the absence of SW cloud radiative effects at the surface, climate models still produce a range of different circulation responses to prescribed uniform SST warming (e.g., Stevens and Bony 2013; Voigt and Shaw 2016). In this case, the spread in the circulation response cannot be due to the spread in the SST response and thus in SW cloud radiative effects (Ceppi et al. 2012, 2014; Ceppi and Hartmann 2016; Ceppi and Shepherd 2017). Rather, it must be due to the changes in atmospheric temperatures that are mediated by processes other than the uniform SST increases (Sherwood et al. 2015). In cloud-locking experiments similar to those used in Ceppi and Hartmann (2016) and Ceppi and Shepherd (2017) but with fixed SSTs, Voigt and Shaw (2015) find that half of the jet shift can be attributed to variations in LW cloud radiative effects, and that model differences in LW cloud radiative changes lead to model differences in jet shifts in two CMIP5 models. Voigt and Shaw (2016) further studied the impact of cloud radiative changes associated with regional cloud changes, and found that 1) the rising of tropical high clouds and 2) the rising and poleward shift of midlatitude high clouds contribute roughly equally to the poleward jet shift, and are qualitatively robust in the two CMIP5 aquaplanet models that they analyzed. The cloud radiative changes associated with high-latitude low-cloud changes were found to have a relatively modest effect and were found only in one model.

Despite widespread evidence that cloud radiative feedbacks influence the jet response to climate change, the underlying mechanisms whereby this occurs have not been fully elucidated. In this study, we provide novel insight into the influence of cloud radiative effect on the jet response to climate change by exploiting the model output from the Clouds On-Off Klimate Intercomparison Experiment (COOKIE) simulation (Stevens et al. 2012) using the Atmospheric Model Intercomparison Project (AMIP) configuration, in conjunction with experiments run with an idealized dry GCM. The effects of clouds on changes in surface SW radiation under climate change are excluded in this approach since SSTs are prescribed. Fixing SSTs allows us to focus on the role of changes in atmospheric cloud radiative effects (ACRE) on the circulation, as in Voigt and Shaw $(2015,2016)$.

Our hypothesis is that changes in ACRE act to enhance the poleward jet shift under climate change by increasing the baroclinicity in the upper troposphere due to the systematic lifting of high clouds and their attendant ACRE. The results reveal that the lifting of high clouds contributes to the poleward shift of the jet not only in cloud-locking experiments (Voigt and Shaw 2015) but also in experiments run in the COOKIE framework. The systematic lifting of tropopause height and high clouds is strongly constrained by clear-sky radiative cooling and thus water vapor concentrations (Hartmann and Larson 2002; Kuang and Hartmann 2007; Zelinka and Hartmann 2010; Popke et al. 2013; Thompson et al. 2017). Thus the influence of rising high clouds on the amplitude of the jet shift under climate change may be viewed as a robust thermodynamic constraint on climate change that arises from the ClausiusClapeyron relation. The hypothesis is tested without interactive SSTs. How the SST pattern would respond to the rise of upper-level clouds and further alter the result of the atmospheric circulation responses would need to be further tested using coupled GCMs.

The paper is organized as follows: Section 2 describes the details of the COOKIE simulations, the idealized dry GCM simulations, and diagnostic techniques. Section 3 examines the impact of ACRE on the circulation response to global warming in the COOKIE simulations, tests our hypothesis in idealized dry GCM simulations, and investigates the intermodel spread in the role of ACRE in enhancing the jet shift. Section 4 reviews the key conclusions.

\section{Model and methods}

\section{a. The COOKIE simulations}

The influence of ACRE on the large-scale atmospheric circulation response to climate change is explored in the AMIP-type COOKIE simulations, which were run under the auspices of the Cloud Feedback Model Intercomparison Project (CFMIP). The COOKIE project has six numerical models available for analyses: the L'Institut Pierre-Simon Laplace (IPSL) Coupled Model (Dufresne et al. 2013), version 5A, low resolution (IPSLCM5A-LR; Hourdin et al. 2013a) and version 5B, low resolution (IPSL-CM5B-LR; Hourdin et al. 2013b); the CNRM Coupled Global Climate Model, version 5 (CNRM-CM5; Voldoire et al. 2013); the Hadley Centre 
Global Environment Model, version 2-Atmosphere and land (HadGEM2-A; Collins et al. 2008); ECHAM6 [atmospheric component of the Max Planck Institute for Meteorology (MPI-M) Earth system model; Stevens and Bony 2013]; and the MRI Coupled Atmosphere-Ocean General Circulation Model, version 3 (MRI-CGCM3; Yukimoto et al. 2012). The detailed model descriptions are provided in Li et al. (2017, Table 1).

We focus on results based on the atmospheric component of the IPSL-CM5A-LR, which has vertically resolved cloud radiative heating rates available for the COOKIE simulations and has also been used in earlier studies on the role of climatological ACRE on the general circulation of the atmosphere in the current climate (Fermepin and Bony 2014; Li et al. 2015, 2017). We examine the intermodel spread of the circulation responses to warming in other numerical models.

The COOKIE simulations include two primary types of experiments, both of which are run with an AGCM forced with the same observed monthly SSTs over the period 1979-2008: 1) control simulations that include the full suite of model ACRE ("ACREon" experiments), and 2) perturbed simulations in which the model ACRE are turned off in the radiative computation ("ACREoff" experiments). In our study, we use the following three sets of 30-yr-long simulations (Stevens et al. 2012):

- "Control_ACREon" and "Control_ACREoff" simulations, in which monthly mean SSTs are prescribed from observations over the period 1979-2008 [referred to as "amip" and "offamip," respectively, in Stevens et al. (2012)]

- "4K_ACREon" and "4K_ACREoff" simulations, in which SSTs are raised uniformly by $4 \mathrm{~K}$ relative to their 1979-2008 values [referred to as "amip4K" and "offamip4K," respectively, in Stevens et al. (2012)]

- " $4 \times \mathrm{CO}_{2}$ ACREon" and " $4 \times \mathrm{CO}_{2}$ ACREoff" simulations, in which $\mathrm{CO}_{2}$ concentrations are quadrupled relative to their preindustrial values while SSTs are fixed at their 1979-2008 values [referred to as "amip $4 \times \mathrm{CO}_{2}$ " and "offamip $4 \times \mathrm{CO}_{2}$," respectively, in Stevens et al. (2012)]

We explore the differences between the following sets of experiments (analogous differences are explored to estimate the response to $4 \times \mathrm{CO}_{2}$ runs in the COOKIE simulations):

1) $4 \mathrm{~K} \_$ACREon minus Control_ACREon: This difference estimates the effects of 4-K surface warming on the atmospheric circulation when ACRE are turned on.

2) 4K_ACREoff minus Control_ACREoff: This difference estimates the effects of 4-K surface warming on the atmospheric circulation when ACRE are turned $o f f$.

3) The difference between 1 and 2: The differences between 1 and 2 are zero if ACRE have no effect on the circulation and its response to surface warming. Thus the differences between 1 and 2 provide an estimate of the role of ACRE on the circulation response to global warming.

\section{b. Interpretation of results based on the COOKIE experiments}

As mentioned above, the difference between 1 and 2 reflects the influence of ACRE on the circulation response to climate change in the COOKIE framework. When working in the COOKIE framework, the influence of ACRE on the jet shift can be further divided into two components: 1) a component due to the effects on the circulation response of the changes in ACRE that occur under climate change, and 2) a component due to the effects of ACRE on the base-state climatologicalmean circulation which, in turn, influence the circulation response to warming (i.e., the circulation response to external forcing is a function of the base state). The two components can be isolated as follows.

The climate of the control and global warming states can be denoted as T1 and T2, respectively. The ACRE have three different states: A0 (ACRE are turned off), A1 (ACRE from the control simulation), and A2 (ACRE from the 4K simulation). Following this notation, the four COOKIE climate change simulations mentioned above can be written as:

- T1A1 (Control_ACREon)

- T2A2 (4K_ACREon)

- T1A0 (Control_ACREoff)

- T2A0 (4K_ACREoff)

The response of the circulation to 4-K surface warming with interactive ACRE can be expressed as T2A2 - T1A1. The response includes two components: 1) the change in the base state due to the increase in temperature from $\mathrm{T} 1$ to $\mathrm{T} 2$, and 2) the change in the circulation due to the change in ACRE state from A1 to A2. To separate the effects of 1) global warming while holding ACRE fixed from 2) changes in ACRE while holding the base state fixed, the total response T2A2 - T1A1 can be expanded as

$$
\begin{aligned}
\mathrm{T} 2 \mathrm{~A} 2-\mathrm{T} 1 \mathrm{~A} 1= & \frac{1}{2}[(\mathrm{~T} 2 \mathrm{~A} 2-\mathrm{T} 2 \mathrm{~A} 1)+(\mathrm{T} 1 \mathrm{~A} 2-\mathrm{T} 1 \mathrm{~A} 1)] \\
& +\frac{1}{2}[(\mathrm{~T} 2 \mathrm{~A} 2-\mathrm{T} 1 \mathrm{~A} 2)+(\mathrm{T} 2 \mathrm{~A} 1-\mathrm{T} 1 \mathrm{~A} 1)],
\end{aligned}
$$


Note that T2A1 has the $4 \mathrm{~K}$ base state with ACRE derived from the control climate, and $\mathrm{T} 1 \mathrm{~A} 2$ has the control (no warming) base state with ACRE derived from the $4 \mathrm{~K}$ climate. The first bracketed term on the rhs represents the effects of the changes in ACRE (from A1 to A2) due to global warming on the circulation where the base states are held fixed. This term is analogous to the circulation response that can be attributed to the radiative changes in clouds alone in the cloud-locking framework (Voigt and Shaw 2015; Ceppi and Hartmann 2016). The second bracketed term on the rhs represents the effects of warming (from T1 to T2) on the circulation with ACRE held fixed. This term is analogous to the circulation response that can be attributed to the changes in SSTs or $\mathrm{CO}_{2}$ alone in the cloud-locking framework (i.e., there is no contribution from the changes in clouds; Voigt and Shaw 2015; Ceppi and Hartmann 2016).

Likewise, the response of the circulation to 4-K surface warming without interactive ACRE can be expressed as

$$
\mathrm{T} 2 \mathrm{~A} 0-\mathrm{T} 1 \mathrm{~A} 0 .
$$

As in the second term on the rhs of Eq. (1), this term also reflects the circulation response that can be attributed to the changes in SSTs (or $\mathrm{CO}_{2}$ ) alone in the cloud-locking framework.

Based on Eqs. (1) and (2), the differences in the circulation response to surface warming between the interactive and noninteractive ACRE cases [i.e., $\left(4 \mathrm{~K}_{-}\right.$ ACREon - Control_ACREon) minus (4K_ACREoff Control_ACREoff)] can be decomposed into two contributions:

- $\frac{1}{2}[(\mathrm{~T} 2 \mathrm{~A} 2-\mathrm{T} 2 \mathrm{~A} 1)+(\mathrm{T} 1 \mathrm{~A} 2-\mathrm{T} 1 \mathrm{~A} 1)]$

As mentioned above, this term estimates the effects of the changes in ACRE (from A1 to A2) due to global warming on the circulation where the base states are held fixed, and is analogous to the component of the response that can be attributed directly to cloud changes in the cloud-locking framework.

- $\frac{1}{2}[(\mathrm{~T} 2 \mathrm{~A} 2-\mathrm{T} 1 \mathrm{~A} 2)+(\mathrm{T} 2 \mathrm{~A} 1-\mathrm{T} 1 \mathrm{~A} 1)]-(\mathrm{T} 2 \mathrm{~A} 0-$

This term is derived from the differences between the two noncloud contribution terms: one is analogous to the "noncloud" terms in the cloud-locking method (where the ACRE are held to the A1 and A2 states), and the other is unique to the COOKIE framework (there are no ACRE acting on the base state). This term arises from the fact that 1) simulations run with ACRE (A1 and A2) and without ACRE (A0) have different climatological-mean circulations in both the troposphere and stratosphere, even though surface temperatures are unchanged (e.g., Li et al. 2015, 2017; Watt-Meyer and Frierson 2017), and 2) the circulation response to global warming is sensitive to the climatological-mean state on which the surface warming is applied (Barnes and Hartmann 2010; Kidston and Gerber 2010; Barnes and Polvani 2013; Simpson and Polvani 2016). As such, this term estimates the effect of ACRE on the circulation response to global warming that arises from the effects of ACRE on the climatological-mean circulation.

Hence, a key difference between the COOKIE and cloud-locking methodologies is that (i) the response to warming in the COOKIE framework includes two components: 1) the effects of changes in ACRE on the response to surface warming and 2) the effects of ACRE on the model base state, whereas (ii) the cloud-locking framework isolates the first component.

\section{c. GFDL dry dynamical core}

We test our hypothesis motivated by COOKIE simulations in the Geophysical Fluid Dynamics Laboratory (GFDL) atmospheric dry dynamical core run in the Held and Suarez (1994) framework. The model is forced by Newtonian relaxation to a prescribed zonally symmetric "radiative equilibrium" temperature field, and is damped by linear Rayleigh friction in the planetary boundary layer. The model is run with the same 39 vertical levels as IPSL-CM5A, and at T42 spectral horizontal resolution with a $\nabla^{8}$ hyperviscosity that damps the smallest scales on a 12 -h time scale. It is integrated with a 15 -min time step for 1000 days. The first 200 days are discarded to account for model spinup.

\section{d. Definition of jet latitude}

The latitude of the eddy-driven jet is found by 1) calculating the pressure-weighted average of the zonal winds between 850 - and $700-\mathrm{hPa}$ (i.e., lower levels are used to capture the barotropic component of the flow); 2 ) interpolating cubically onto a $0.1^{\circ}$ latitude grid around the peak of the zonal flow; and 3) finding the latitude of the maximum wind speed between $20^{\circ}$ and $70^{\circ}$ latitude at a $0.1^{\circ}$ interval.

\section{Results}

a. The circulation response to global warming in different forcing scenarios and model configurations

Figure 1a briefly reviews the zonal-mean zonal wind response to abrupt $4 \times \mathrm{CO}_{2}$ forcing in one of the 


\section{Zonal-mean zonal wind response}
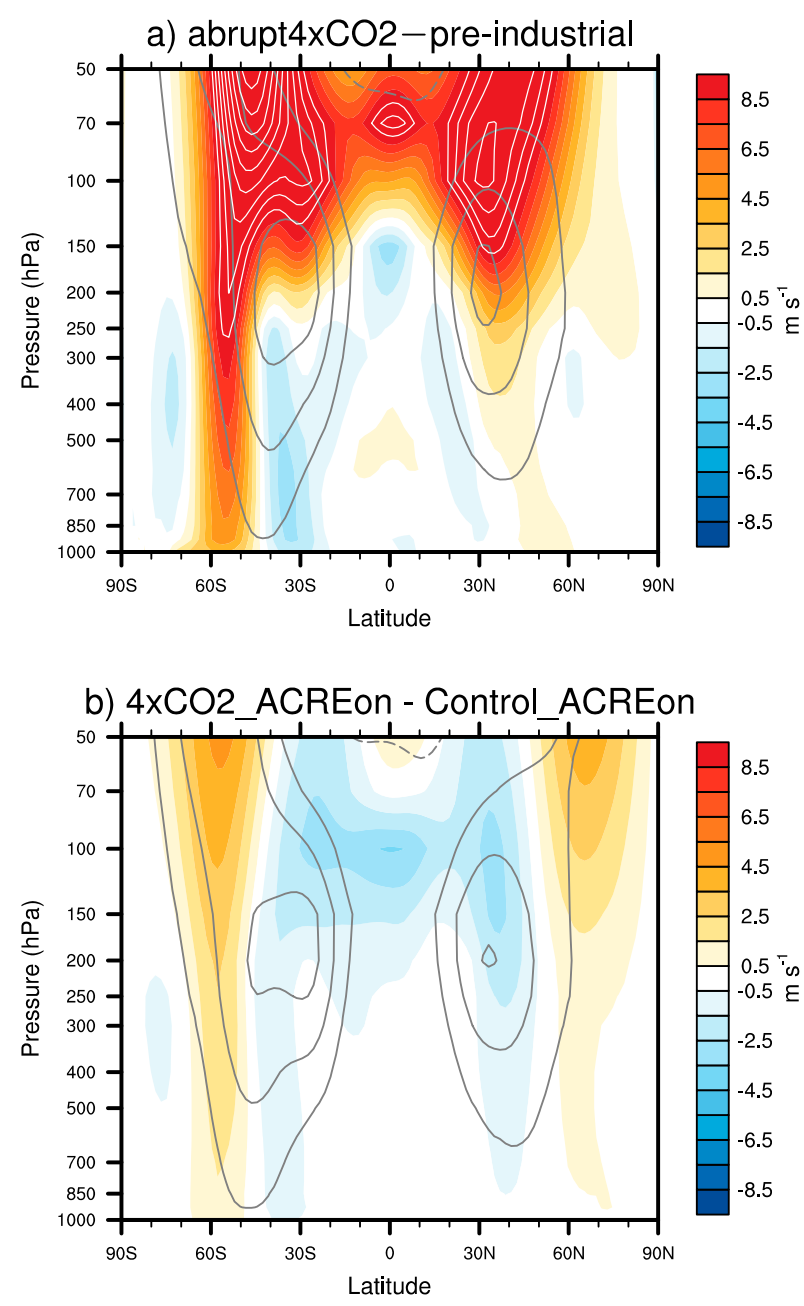

c) 4K ACREon - Control ACREon

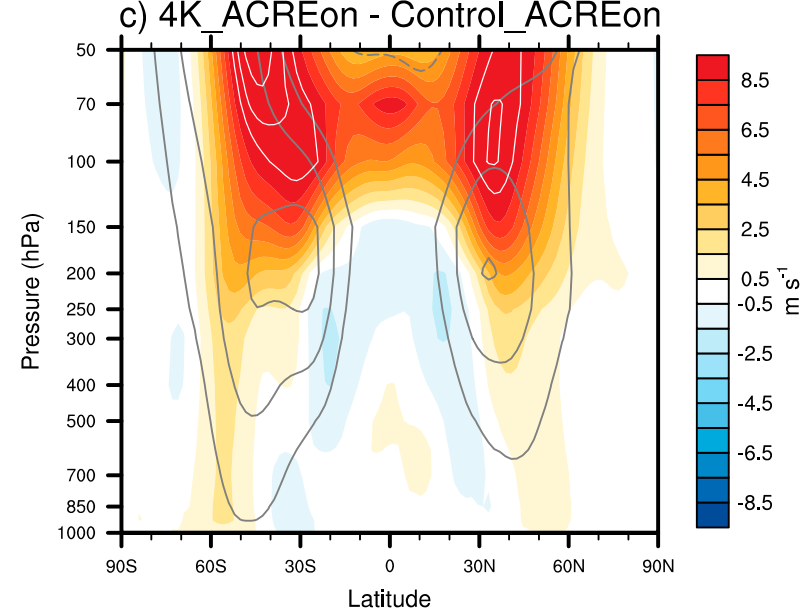

FIG. 1. The response in zonal-mean zonal wind (shading) to climate change in the IPSL-CM5A-LR model. (a) The difference between the abrupt $4 \times \mathrm{CO}_{2}$ (average over the last 50 years) and preindustrial control run (all available years); (b) contribution coupled global climate models that participated in CMIP5 (i.e., IPSL-CM5A-LR consistent with the one used in the COOKIE framework). Consistent with previous studies (Hall et al. 1994; Kushner et al. 2001; Yin 2005; Barnes and Polvani 2013; Vallis et al. 2015), increasing $\mathrm{CO}_{2}$ and associated warming leads to a robust poleward shift in the midlatitude $\mathrm{SH}$ jet and a relatively weak shift in the Northern Hemisphere $(\mathrm{NH})$ jet. Figure 1a suggests that the IPSL-CM5A-LR model behaves much like the multimodel ensemble means from all 26 CMIP5 models [Fig. 1 in Grise and Polvani (2014)].

The total response to $4 \times \mathrm{CO}_{2}$ in coupled simulations shown in Fig. 1a can be approximately decomposed into two components (e.g., Deser and Phillips 2009; Bony et al. 2013; Grise and Polvani 2014): 1) the component due to the direct atmospheric radiative forcing of $\mathrm{CO}_{2}$ while holding SSTs fixed (i.e., $4 \times \mathrm{CO}_{2}$ ACREon Control_ACREon; Fig. 1b), and 2) the component due to increasing SSTs while holding $\mathrm{CO}_{2}$ fixed (approximate to spatially uniform $4-\mathrm{K}$ increases in SST, i.e., the 4K_ACREon - Control_ACREon; Fig. 1c). The results in Figs. $1 \mathrm{~b}$ and $1 \mathrm{c}$ (and the other five available COOKIE models; not shown) suggest that the poleward shift of the jet is mostly due to the increases in surface temperature and attendant changes in atmospheric temperature, whereas the direct radiative forcing of $\mathrm{CO}_{2}$ plays a much weaker role (Grise and Polvani 2014).

How different (or similar) would these results be in the absence of ACRE? We answer this question by using the COOKIE experiments to assess the role of ACRE on the circulation response to the direct effects of rising SSTs (Fig. 2) and increasing $\mathrm{CO}_{2}$ (Fig. 3). The left column of Fig. 2 shows the effects of 4-K warming on zonalmean temperature and zonal wind changes when ACRE are on (i.e., 4K_ACREon-Control_ACREon; note that Fig. 2a is identical to Fig. 1c), and the center column of Fig. 2 shows the effects of 4-K warming on the corresponding changes when ACRE are off (i.e., 4K_ACREoff - Control_ACREoff). As discussed in section $2 \mathrm{~b}$, the differences between the left and center columns of Fig. 2 can be viewed as the total effects of ACRE on the circulation response to global warming

from direct atmospheric $\mathrm{CO}_{2}$ forcing only $\left(4 \times \mathrm{CO}_{2}\right.$ ACREon Control_ACREon); (c) contribution from increasing SSTs only (4K_ACREon - Control_ACREon). Gray contours denote the corresponding climatology in each control case (contour interval: $10 \mathrm{~m} \mathrm{~s}^{-1}$ ). In each panel, zonal-mean zonal wind responses larger than $9.5 \mathrm{~m} \mathrm{~s}^{-1}$ are indicated as white contours at $1 \mathrm{~m} \mathrm{~s}^{-1}$ intervals. 
Response with ACRE (4K_ACREon - Control_ACREon)
Response without ACRE (4K_ACREoff - Control_ACREoff)
Differences in the response
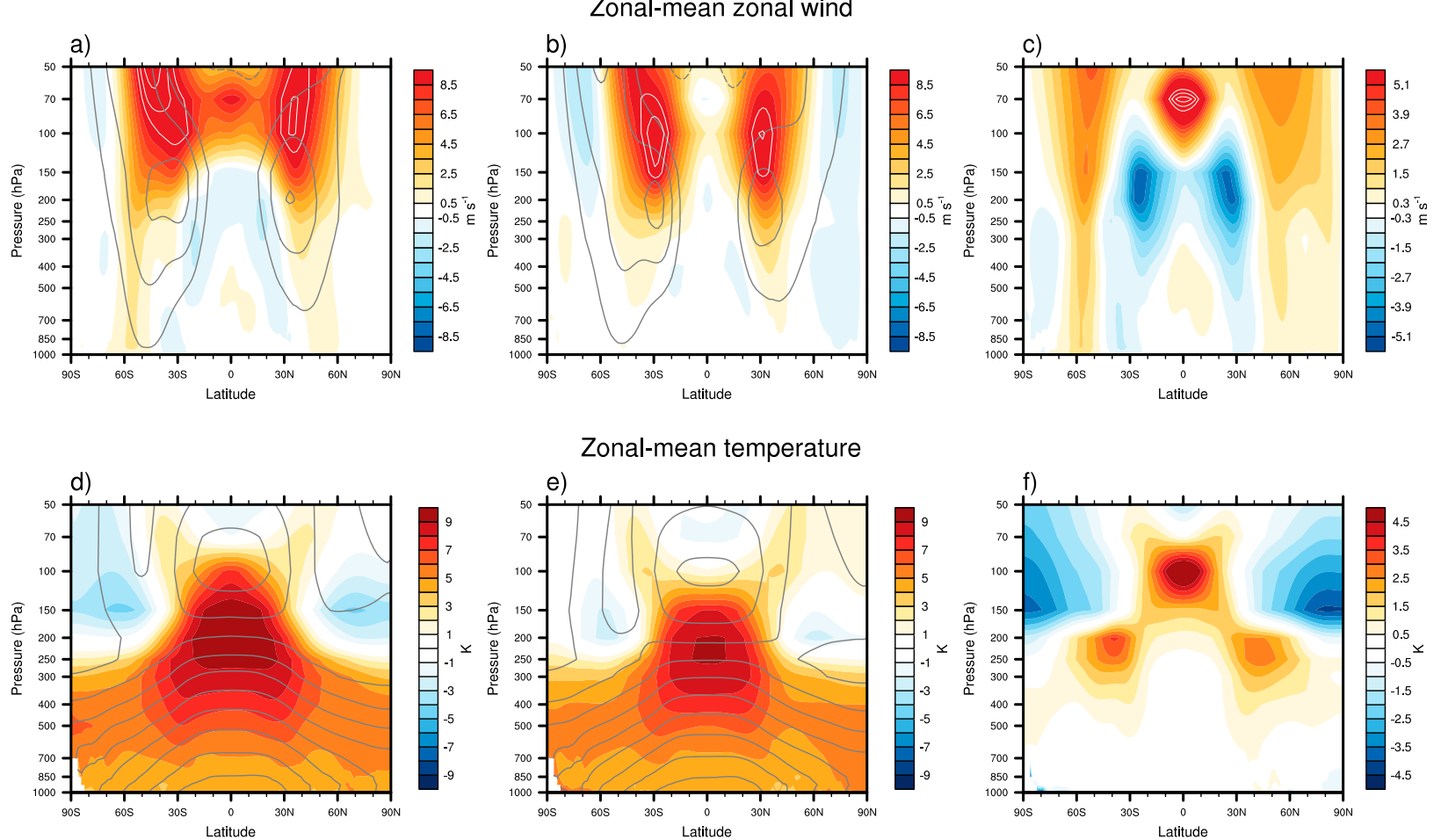

FIG. 2. Circulation response (shading) to 4-K warming when ACRE are (left) on and (center) off, and (right) the differences between left and center columns. (a) Reproduction from Fig. 1c. (a)-(c) The zonal-mean zonal wind; (d)-(f) the zonal-mean temperature. Zonalmean zonal wind responses larger than $9.5 \mathrm{~m} \mathrm{~s}^{-1}$ are indicated as white contours at $1 \mathrm{~m} \mathrm{~s}^{-1}$ intervals in (a) and (b). Zonal-mean zonal wind responses larger than $5.7 \mathrm{~m} \mathrm{~s}^{-1}$ are indicated as white contours at $0.6 \mathrm{~m} \mathrm{~s}^{-1}$ intervals in (c). Gray contours denote the corresponding climatology (contour interval of zonal-mean zonal wind: $10 \mathrm{~m} \mathrm{~s}^{-1}$; contour interval of zonal-mean temperature: $10 \mathrm{~K}$ ) in (left) Control_ ACREon and (center) Control_ACREoff.

(right column of Fig. 2). Comparing the left and center columns, the poleward shift of the jet has larger amplitude when ACRE are included in the simulations (Fig. 2c). The results in Fig. 2c support earlier findings that much of the total jet shift is due to cloud radiative effects (Voigt and Shaw 2015, 2016; Ceppi et al. 2014; Ceppi and Hartmann 2016; Ceppi and Shepherd 2017).

The vertical structures of the zonal-mean temperature responses to 4-K warming (Figs. 2d,e) are dominated by large warming in the tropical upper troposphere, which is as expected since the tropics closely follow the moist adiabatic lapse rate. The tropical upper-tropospheric warming gives rise to 1) increases in the uppertropospheric meridional temperature gradient and 2) increases in tropical vertical stability, both of which contribute to the poleward shift of the midlatitude jet (e.g., Lorenz and DeWeaver 2007; Chen and Held 2007; Chen et al. 2008; Frierson 2008; Butler et al. 2010). The weak cooling in the polar lower stratosphere in the response to surface warming has been noted in previous studies (Grise and Polvani 2017; Singh and O'Gorman
2012; Vallis et al. 2015) and is consistent with the rising tropopause height by construction [see also Fig. 11 of Vallis et al. (2015)].

Consistent with the larger amplitude of the poleward shift of the jet in Fig. 2c, the meridional temperature gradient in the upper troposphere between 100 and $300 \mathrm{hPa}$ is also much larger when ACRE are included in the simulation (Fig. 2f). The difference in the responses of static stability is expected to be larger in the tropics but smaller in the extratropics when ACRE are included, which may also contribute to the changes in baroclinicity. The inferred influence of ACRE on the response to $4-\mathrm{K}$ warming shown in Figs. $2 \mathrm{c}$ and $2 \mathrm{f}$ is very similar to the inferred influence of cloud LW radiative forcing in the climate change experiments run in Voigt and Shaw (2016; compare with their Fig. 6i).

Figure 3 shows analogous results for the $4 \times \mathrm{CO}_{2}$ simulations (i.e., SSTs are held fixed; note that Fig. 3a is identical to Fig. 1b). The vertical structure of the zonalmean temperature response to the $\mathrm{CO}_{2}$ direct effect is characterized by stratospheric cooling, as expected from the 
Response with ACRE (4xCO2_ACREon - Control_ACREon)

\section{Response without ACRE \\ (4xCO2_ACREoff - Control_ACREoff)}

Differences in the response
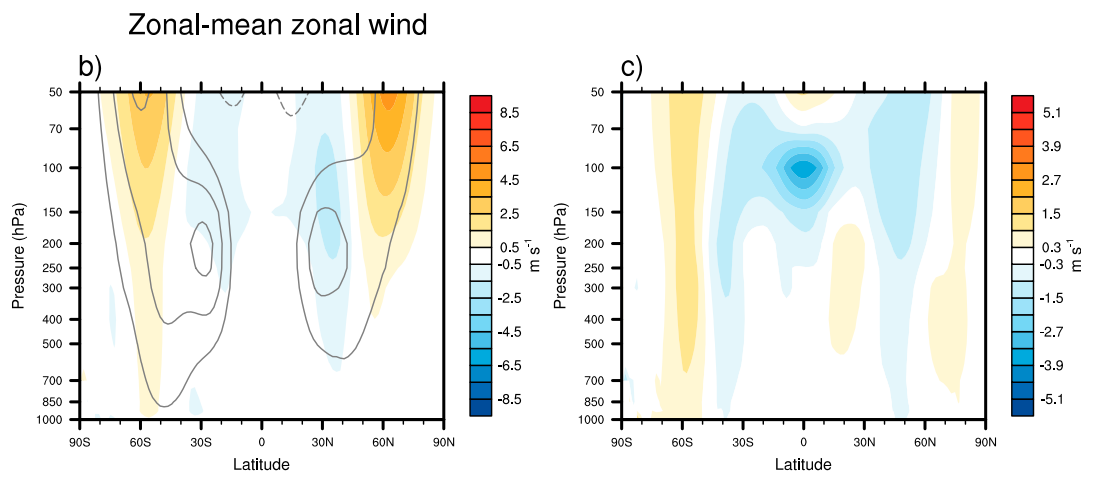

Zonal-mean temperature

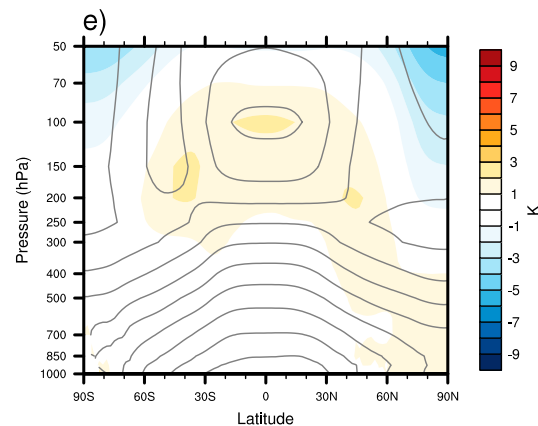

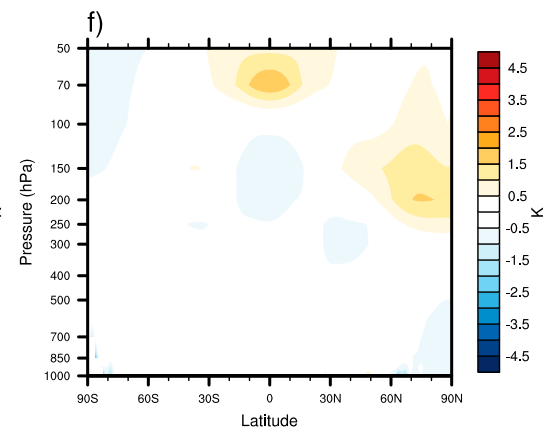

FIG. 3. As in Fig. 2, but for the circulation response (shading) to $4 \times \mathrm{CO}_{2}$ when ACRE are (left) on and (center) off, and (right) the differences between left and center columns. (a) Reproduction from Fig. 1b. (a)-(c) The zonal-mean zonal wind; (d)-(f) the zonal-mean temperature. Gray contours denote the corresponding climatology in (left) Control_ACREon and (center) Control_ACREoff.

increased LW emission due to increasing $\mathrm{CO}_{2}$ (Fig. 3d). As such, the meridional temperature gradient is enhanced in the upper troposphere, and there is a weak poleward shift of the jet (Fig. 3a). As is the case for increasing SSTs (Fig. 2), the inclusion of ACRE leads to a larger shift in the SH jet (Fig. 3c). However, the effects of ACRE on the jet responses to increasing $\mathrm{CO}_{2}$ are relatively weak when SSTs are held fixed (cf. Figs. 2c and 3c).

In the following, we will focus on understanding the role of ACRE on the zonal-mean eddy-driven jet response in the $+4-\mathrm{K}$ warming experiments. As noted above, the jet response to $4-\mathrm{K}$ warming is associated with an increased baroclinicity in the upper troposphere, and this effect is enhanced when ACRE are turned on. As shown below, the enhancement of the meridional temperature gradient in the upper troposphere by ACRE changes under warming plays a key role in the associated enhancement of the jet shift.

\section{b. Interpretation of the changes in clouds and ACRE in the $+4-K$ warming experiment}

The most prominent features in the cloud response to +4-K warming (Fig. 4a) are increases in cloud fraction above the control high-cloud maximum and decreases in cloud fraction below the control high-cloud maximum, indicating an upward shift in high-level clouds at all latitudes. The upward shift of high-level clouds is expected from the lifting of the tropopause at all latitudes (also see Fig. 5a), which is a robust response in all available COOKIE models (not shown). That the clouds shift with the tropopause is anticipated on the basis of the thermodynamic constraint placed on the temperature of high clouds in both the tropics (Hartmann and Larson 2002; Kuang and Hartmann 2007; Zelinka and Hartmann 2010; Popke et al. 2013), and the extratropics (Thompson et al. 2017). The lifting of the tropopause and deepening of the troposphere in response to warming is consistent with previous studies (Santer et al. 2003; Singh and O'Gorman 2012; Vallis et al. 2015). The most prominent features in the ACRE response to +4-K warming (Fig. 4b) are increases in ACRE above the control cloud radiative heating maximum, and decreases in ACRE above the control cloud radiative heating minimum. As such, the same basic lifting of high-level clouds (Fig. 4a) extends to ACRE (Fig. 4b) across all latitudes. 
Response with ACRE (4K_ACREon - Control_ACREon)

a) Cloud fraction

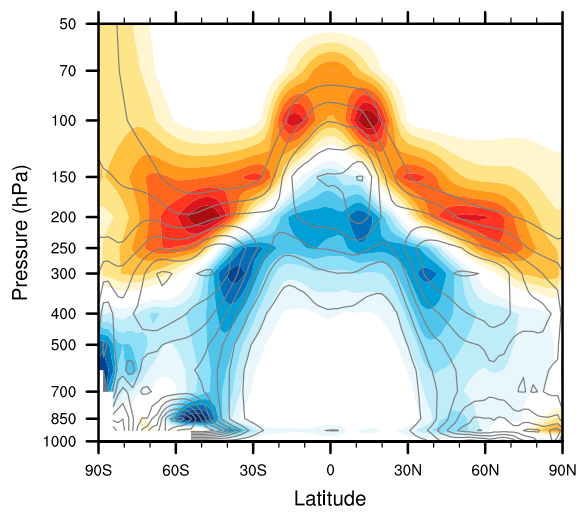

b) Cloud radiative heating rate (ACRE)
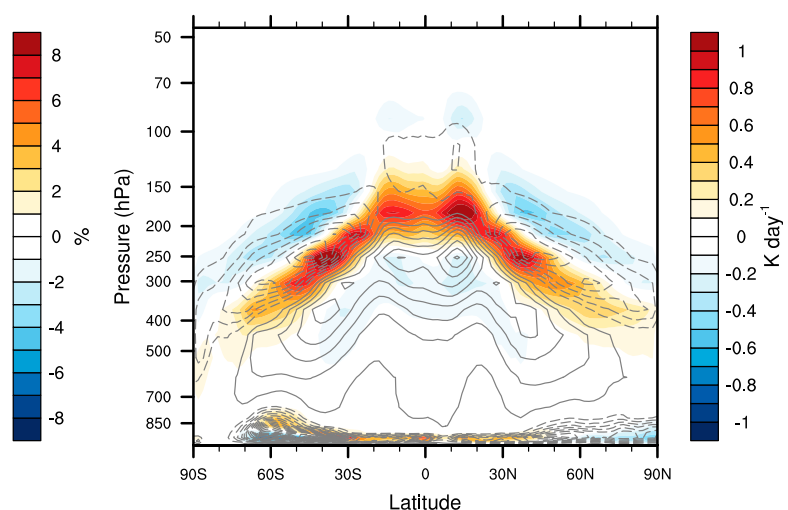

FIG. 4. The response in (a) cloud and (b) cloud radiative effects (ACRE) to 4-K warming when ACRE are on. Gray contours denote the corresponding climatology (contour interval of cloud fraction: 4\%; contour interval of cloud radiative heating rate: $0.15 \mathrm{~K} \mathrm{day}^{-1}$ ) in the Control_ACREon.

Figure 5 explores the responses to surface warming in tropopause height, cloud fraction, and ACRE in pressure (top) and temperature (bottom) coordinates. The tropopause (Fig. 5a) and the pressure of the maximum cloud fraction (Fig. 5b) are both lifted by $\sim 25 \mathrm{hPa}$ in the tropics and by $\sim 50 \mathrm{hPa}$ in the extratropics in the
"4K_ACREon" (dashed line) simulations as compared to the "Control_ACREon" (solid line). The pressure of the maximum (red) and minimum (blue) ACRE is lifted by $\sim 50 \mathrm{hPa}$ globally (Fig. $5 \mathrm{c}$ ). Importantly, the tropopause, cloud fraction maximum, and ACRE maximum/minimum stay at roughly the same temperature, particularly at
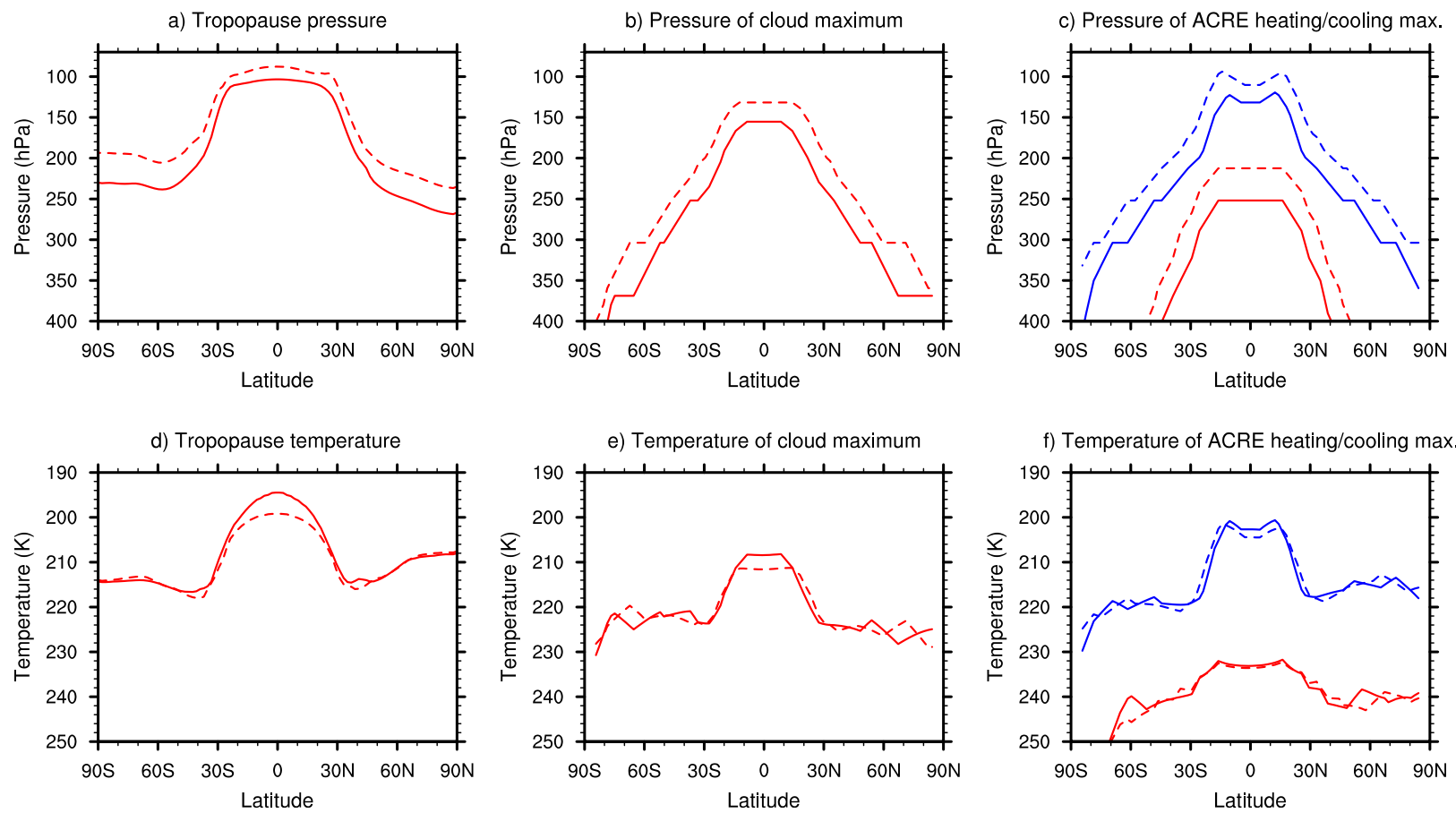

FIG. 5. The (a)-(c) pressure and (d)-(f) temperature of the (left) tropopause, (center) maximum in cloud fraction, and (right) maximum/ minimum in ACRE as a function of latitude. The solid lines indicate results from Control_ACREon. The dashed lines indicate results from $4 \mathrm{~K} \_$ACREon. Red (blue) lines in the right panels indicate results for the pressure and temperature of the maximum warming (cooling) in the ACRE. Results are smoothed with a latitudinal running-mean filter for display purposes. 


\section{Changes in cloud and cloud radiative heating}

a) 4K_ACREon-control_ACREon

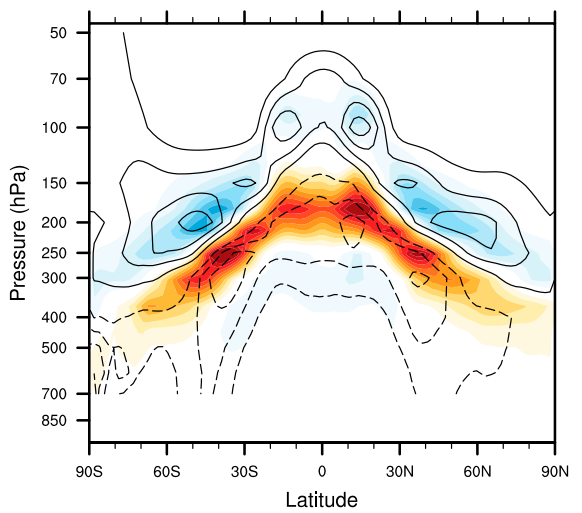

b) control_ACREon ( $p+d p)$-control_ACREon ( $p)$
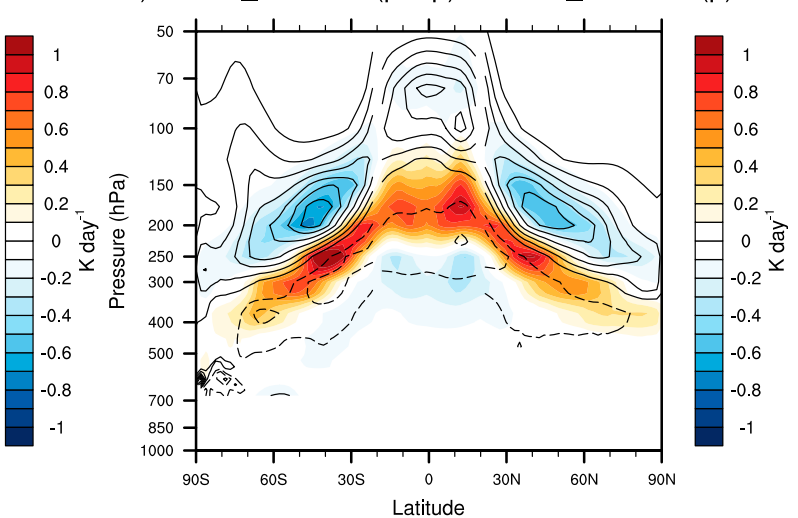

FIG. 6. (a) The simulated differences in clouds (contours; contour interval: 1\%) and ACRE (shading) between 4K_ACREon and Control_ACREon. (b) The constructed differences in clouds (contours) and ACRE (shading) between Control_ACREon centered at $(\varphi, p+\delta p)$ and Control_ACREon centered at $(\varphi, p)$, where $\delta p$ is $25 \mathrm{hPa}$ in the tropics and $50 \mathrm{hPa}$ in the extratropics for cloud field, and $\delta p$ is $50 \mathrm{hPa}$ for ACRE at all latitudes. Values below $700 \mathrm{hPa}$ are masked out.

extratropical latitudes, consistent with fixed anvil temperature (FAT) physics at tropical (Hartmann and Larson 2002) and extratropical (Thompson et al. 2017) latitudes. The tropical tropopause and high clouds move to a slightly higher temperature, consistent with the slight increase in static stability at tropical latitudes, which act to move the level of largest clear-sky vertical mass fluxes to a slightly warmer level (Zelinka and Hartmann 2010).

To test whether the spatial pattern of the changes in cloud fraction under warming can be reproduced by a simple vertical shift, we lift the cloud fraction in the "Control_ACREon" run at each latitude and pressure by $25 \mathrm{hPa}$ in the tropics and $50 \mathrm{hPa}$ in the extratropics (as inferred from Fig. 5b). Similarly, we also lift ACRE in the "Control_ACREon" run at each latitude and pressure by $50 \mathrm{hPa}$ (as inferred from Fig. $5 \mathrm{c}$ ). Figure $6 \mathrm{~b}$ shows the results of the calculation. As is apparent in the figure, the patterns of clouds (contours) and ACRE (shading) that result from lifting both fields from their control configurations (Fig. 6b) yield patterns that strongly resemble the actual changes in both fields (Fig. 6a; reproduced from shading in Figs. 5a and 5b). The actual cloud fraction changes (Fig. 6a) exhibit slightly smaller positive anomalies and larger negative anomalies than those found in the constructed cloud fraction changes (Fig. 6b). These features likely arise from the net reduction in mid- and high-level cloud fraction found under global warming scenarios (Zelinka et al. 2013; Bony et al. 2016; Voigt and Shaw 2016).

The changes in cloud radiative effects are physically consistent with the lifting of upper-level clouds.
Specifically, the lifting leads to anomalous warming due to ACRE beneath the level where the cloud fraction anomalies are positive, and anomalous cooling above that level. Because of the meridional slope of the tropopause, the pattern of ACRE associated with rising high clouds has 1) a pronounced meridional gradient, and 2) an effect to stabilize the tropics and destabilize the extratropics in the upper troposphere. Therefore, the changes in ACRE under warming serve to enhance the baroclinicity in the upper-tropospheric midlatitudes, which subsequently acts to increase the poleward shift of the jet.

In the next subsection, we will use the idealized dry GCM to test the effects of the anomalous ACRE associated with a global lifting of the tropopause on the poleward shift of the jet.

\section{c. The circulation response to warming-induced ACRE changes in an idealized dry GCM}

To explore the isolated effects of the changes in ACRE associated with surface warming on the poleward shift of the jet, we force an idealized dry GCM with the pattern of ACRE obtained from the comprehensive GCM. As described in section 2c, in the control simulation of the idealized dry GCM, the atmospheric temperature is driven by Newtonian relaxation toward the prescribed radiative equilibrium temperature profile from Held and Suarez (1994). In the perturbed simulation, we add a thermal forcing as a diabatic heating in the temperature tendency equation in the idealized dry GCM. The differences in the circulation between the long-term means of the perturbed and control simulations of the idealized dry GCM can be considered as the 


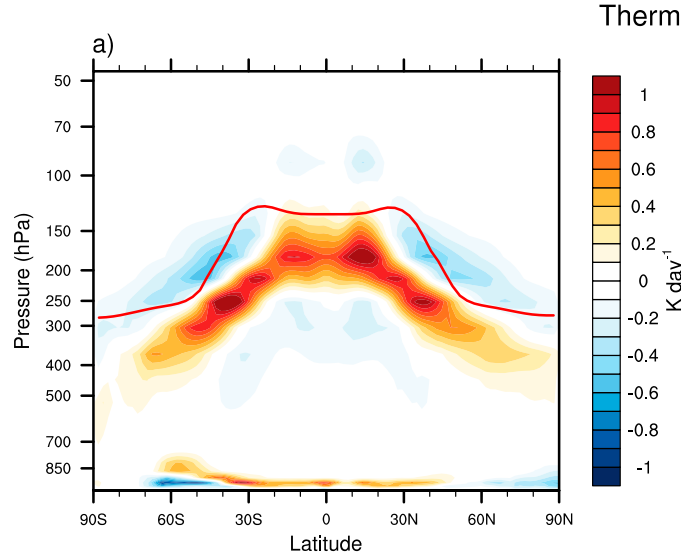

Thermal forcing
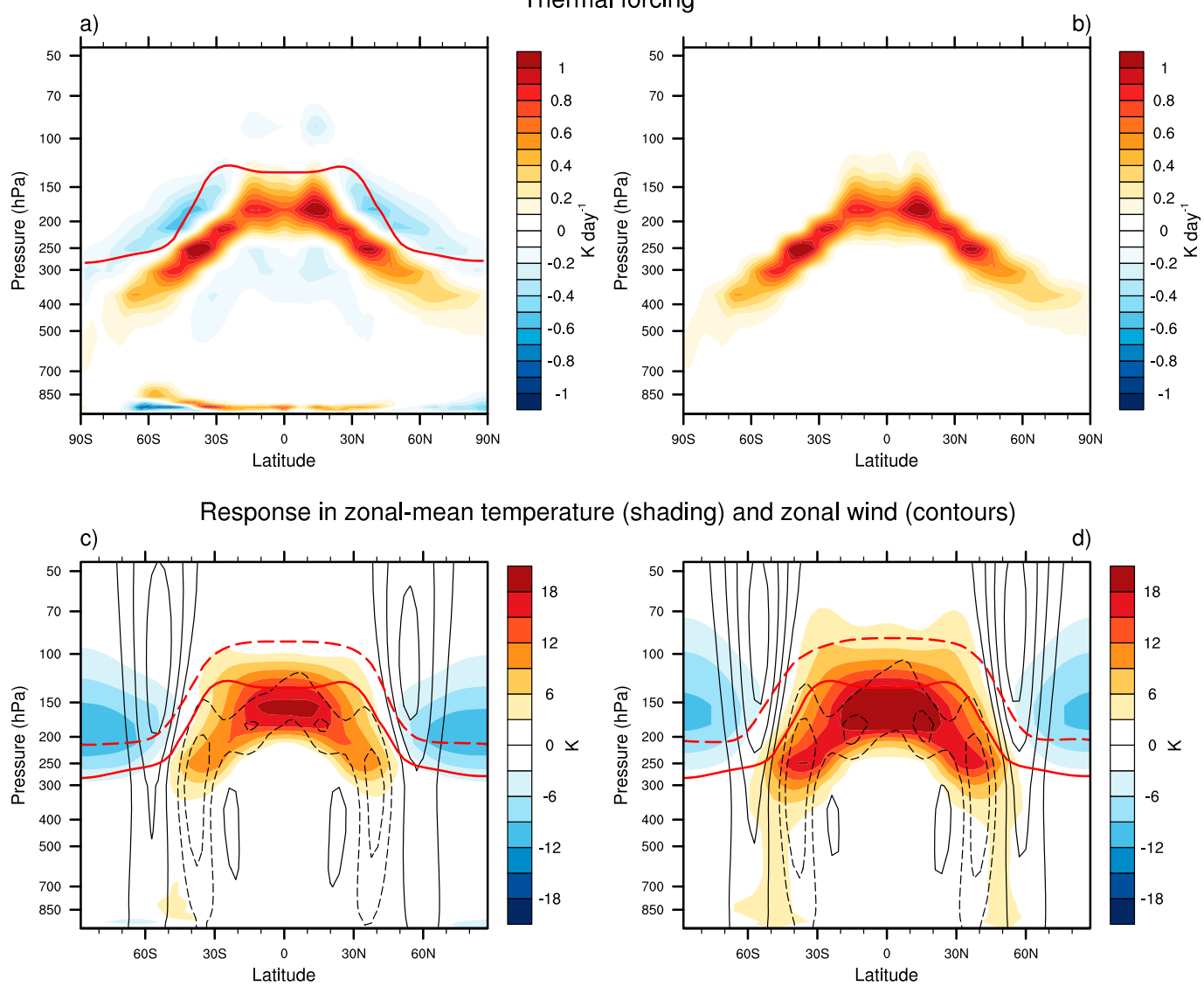

FIG. 7. (a) Thermal forcing added in the idealized dry GCM obtained from differences in ACRE between 4K_ACREon and Control_ACREon (reproduced from the shading in Fig. 4a). (b) As in (a), but for only the radiative warming component of the ACRE. (c),(d) The response in zonal-mean temperature (shading) and zonal wind (contours; contour interval: $5 \mathrm{~m} \mathrm{~s}^{-1}$ ) to the thermal forcings in (a) and (b), respectively. Solid and dashed lines are the tropopause height in the control and perturbed simulations, respectively.

"response" to that particular thermal forcing. A similar approach was exploited by Voigt and Shaw (2016), who used an idealized dry GCM to study the jet response to global and regional CRE.

The top panels in Fig. 7 show the two thermal forcings applied here, and the bottom panels show the responses in the zonal-mean temperature field (shading) and wind field (contours). The thermal forcing in Fig. 7a is derived from the change in ACRE found between the control and $+4-\mathrm{K}$ experiments (reproduced from shading in Figs. $4 \mathrm{~b}$ and $6 \mathrm{a})$. The response to the thermal forcing includes (Fig. 7c) 1) warming in the tropical troposphere centered at $\sim 150 \mathrm{hPa}$, juxtaposed against relatively weak cooling in the lower stratosphere poleward of $\sim 50^{\circ}, 2$ ) westerly changes in the zonal flow centered around $55^{\circ}$ extending upward into the stratosphere, juxtaposed against easterly changes centered around $35^{\circ}$ below $100 \mathrm{hPa}$, and 3) an increase in the tropopause height globally (comparing the dashed and solid contours).
Overall, the structure of the changes in the zonalmean temperature and zonal-wind fields in the idealized dry GCM (Fig. 7c) bear a strong resemblance to the effects of ACRE on the circulation in the 4-K AGCM simulations (cf. Fig. 7c with the right panel in Fig. 2). The most notable exception is that the amplitude of the temperature response is $\sim 4$ times larger in the dry model, which may result from 1) differences in model physics between the full GCM and the dry dynamical core, such as the convective scheme and/or other parameterizations that act to damp the temperature response in the comprehensive GCM (Voigt and Shaw 2016), and/or 2) the fact that the heating imposed in the dry dynamical core does not account for any attendant changes in clear-sky radiative cooling driven by changes in atmospheric water vapor, which will tend to oppose the effects of ACRE (Voigt and Shaw 2015; Ceppi and Shepherd 2017). As discussed below, the stronger amplitude of the upper-tropospheric temperature responses is consistent with the stronger amplitude of the poleward 


\section{a) Tropopause pressure}

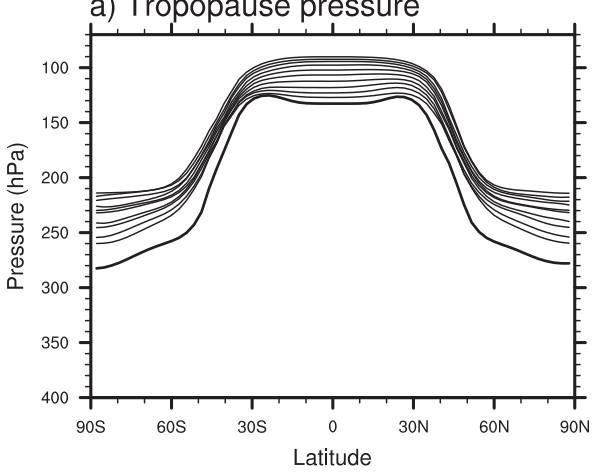

b)

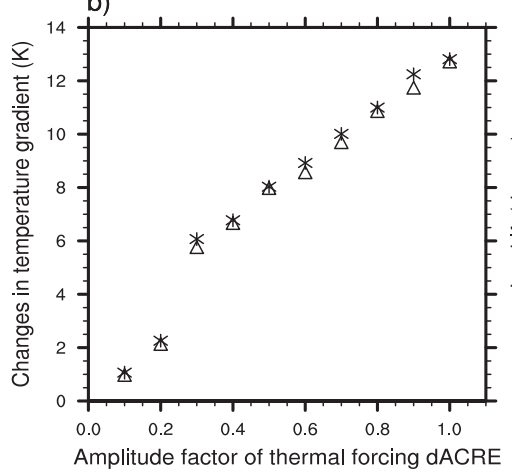

c)

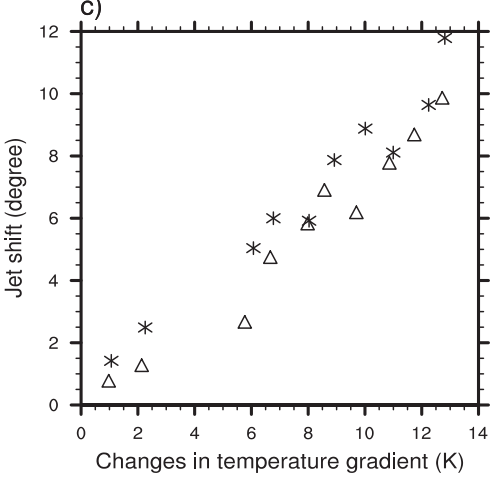

FIG. 8. (a) The tropopause height for each of the 10 idealized dry GCM simulations with amplitude of the thermal forcing multiplied by a factor of $0.1,0.2, \ldots, 1$ (thin lines) and the tropopause height for the control run in the idealized dry GCM (thick line). (b) The relationship between the multiplication factor of the thermal forcing and the amplitude of the equator-to-pole temperature difference in the upper troposphere. (c) The relationship between the amplitude of the equator-to-pole temperature difference in the upper troposphere and the amplitude of the jet shift. The triangles denote the $\mathrm{SH}$, and the stars denote the $\mathrm{NH}$. The upper-tropospheric meridional temperature gradient in the each hemisphere is defined as the difference in temperature averaged over the tropics $\left(0^{\circ}-40^{\circ} \mathrm{S} / \mathrm{N}, 100-300 \mathrm{hPa}\right)$ and high latitudes $\left(40^{\circ}-90^{\circ} \mathrm{S} / \mathrm{N}, 100-300 \mathrm{hPa}\right)$.

jet shift in the dry GCM relative to that in the 4-K AGCM. The key result in Fig. $7 \mathrm{c}$ is that the pattern of ACRE from the comprehensive GCM yields a poleward shift in the idealized dry model jet that bears close resemblance to the enhancement of the jet shift found when ACRE are included in the +4-K AGCM simulations.

We performed a second perturbed simulation forced by the radiative warming component of the ACRE in the upper troposphere in isolation (Fig. 7b). The similarities in the circulation responses between the two perturbed simulations (Figs. 7c,d) suggest that the changes in the midlatitude circulation are predominantly driven by the increased cloud radiative warming in the upper troposphere, and that the cloud radiative cooling in the upper troposphere, in addition to the cloud radiative changes in the middle and lower troposphere that were explored in Voigt and Shaw (2016), play a secondary role in driving the circulation response. Because of the meridional slope of the tropopause and thus the meridional slope of radiative warming from rising high clouds, the warming is expected to 1 ) increase the upper-tropospheric temperature gradient and 2) enhance the static stability on the equatorward side of the jet and weaken the static stability in the extratropics. Both of these factors should contribute to an enhanced poleward jet shift due to the inclusion of ACRE in global warming simulations.

Figure 8 explores the relationships between amplitude of the thermal forcing, the lifting of the tropopause height, the amplitude of the meridional temperature gradient, and the amplitude of the jet shift. The thermal forcing added is similar to what is shown in Fig. 7a but is multiplied by a factor of $0.1,0.2, \ldots, 0.9$. Figure 8 a suggests that the stronger the thermal forcing, the larger the lifting of the tropopause (Fig. 8a). Interestingly, the scatterplots shown in Figs. $8 \mathrm{~b}$ and $8 \mathrm{c}$ suggest a roughly linear relationship between the amplitude of the thermal forcing, the amplitude of the upper-tropospheric meridional temperature gradient, and the amplitude of the jet shifts. There is also a modest hemispheric asymmetry in the response that results from the imposed ACRE. Figure 8 suggests that the upper-tropospheric meridional temperature gradient plays a primary role in the enhanced baroclinicity in the upper troposphere and thus poleward shift of the extratropical jet.

Similar poleward jet shifts have been found in previous idealized dry GCM forced by 1) imposing tropical upper-tropospheric warming (Butler et al. 2010; Sun et al. 2013; Voigt and Shaw 2016), 2) imposing midlatitude upper-tropospheric warming (Lorenz and DeWeaver 2007; Voigt and Shaw 2016), and 3) raising the tropopause height (Lorenz and DeWeaver 2007). The results shown in Figs. 7 and 8 reveal that the changes in ACRE associated with rising high clouds under climate change also lead to robust poleward shifts in the jet. In the appendix, we use the dry GCM to test the relative importance of climatological-mean ACRE versus changes in ACRE on the jet response.

\section{d. The intermodel spread of the jet shift in the COOKIE simulations}

The enhanced jet shift found in response to warming in the COOKIE simulations when ACRE are turned on is robust across different atmospheric models. Figure 9 summarizes and compares the zonal-mean eddy-driven 
a) ACRE on

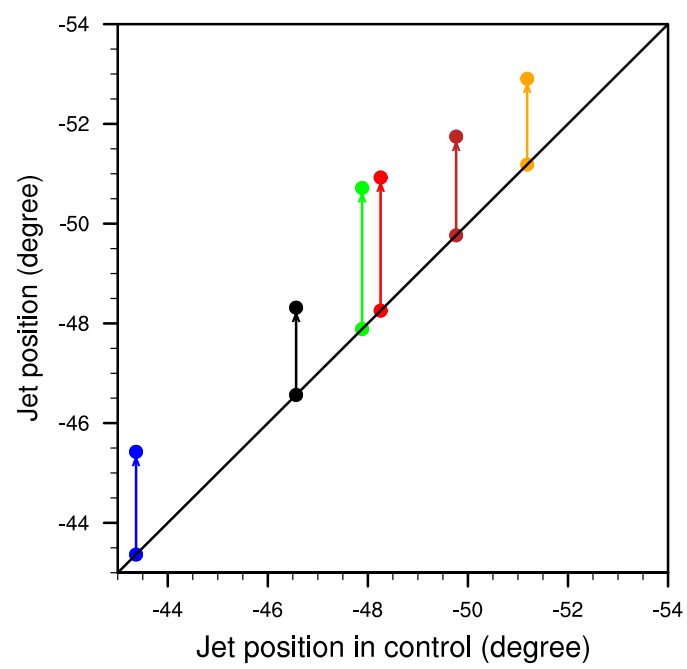

c) ACRE on

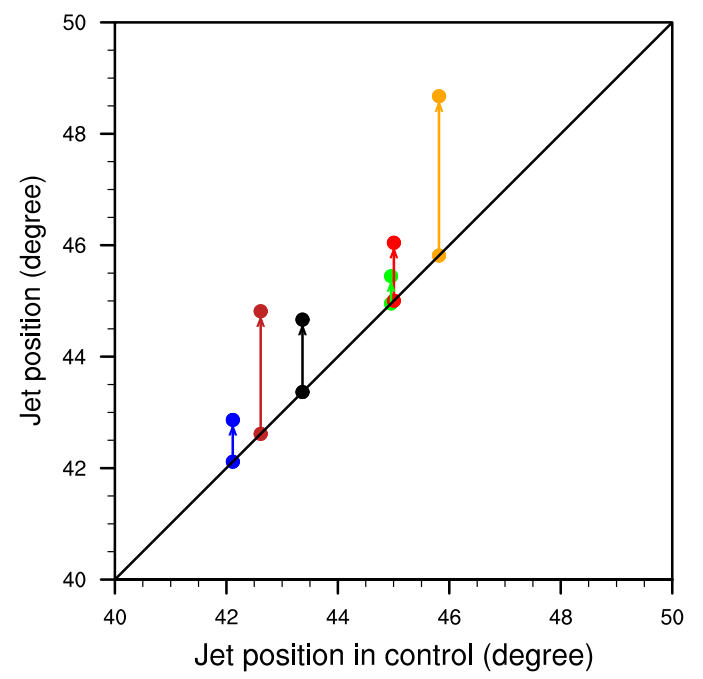

- IPSL-CM5A-LR

- HadGEM2-A
$\mathrm{SH}$

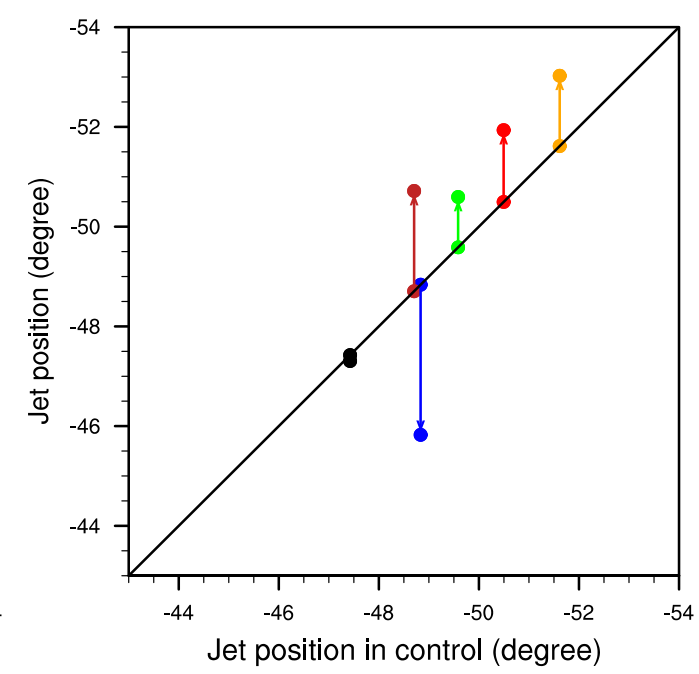

$\mathrm{NH}$

d) ACRE off

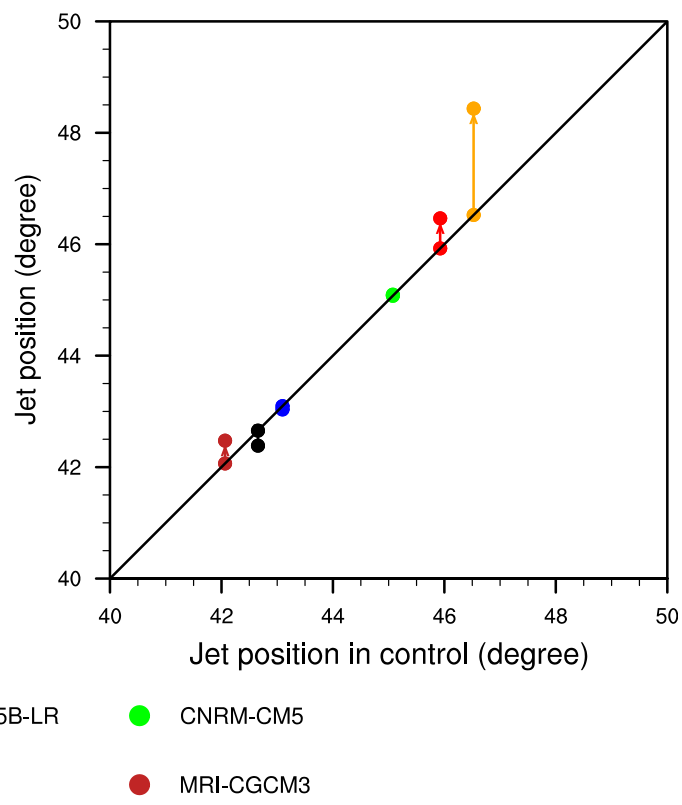

FIG. 9. Mean (a),(b) SH and (c),(d) NH jet positions in the control and +4-K simulations when ACRE are (left) on and (right) off. The jet positions in the control simulations are on the solid diagonal line; the jet positions in the $+4-\mathrm{K}$ experiments are off the diagonal line and indicated by values on the ordinate axis. Arrows connect mean jet positions between the two simulations. Different colored circles denote the different models available from the COOKIE archive.

jet latitude in the SH (top) and NH (bottom) for each AGCM in the control (points on the solid diagonal line) and $+4-K$ simulations (points off the diagonal line) when ACRE are on (left) and off (right). When ACRE are on (left panels), the jet positions in the $+4-\mathrm{K}$ simulations are all above the diagonal line, indicating the poleward shift of the jet. The poleward shift of the jet is about $2^{\circ}-4^{\circ}$ latitude among all six models. When ACRE are off (right panels), the poleward shift of the jet is evidently smaller in magnitude in all cases. Note the IPSL-CM5B behaves very differently from other models in the ACRE off simulation. The results suggest that the enhanced poleward shift of the jet when ACRE are turned on is qualitatively robust across all six COOKIE 
simulations, although the amplitude of the effect shows considerable spread.

The considerable intermodel spread in the impact of ACRE on the poleward jet shift (cf. the left and right panels) could be due to several factors: 1) intermodel variations in the response of the upper-tropospheric meridional temperature gradient to changes in ACRE under surface warming (i.e., the component due to the effects of changes in ACRE on the circulation response), 2) intermodel variations in the response of the climatological-mean circulation to ACRE, which in turn induces differences in the circulation response to surface warming (i.e., the component due to the effects of ACRE on the base-state climatology), and/or 3) intermodel variations in the amplitude and latitude-height structure of the ACRE response to surface warming. It is not possible to quantify factors 1 and 2 in simulations provided in the COOKIE archive, but they could be studied in more detail with additional cloud-locking simulations. It is difficult to verify factor 3 because of the lack of vertically resolved ACRE made available from the COOKIE or CMIP5 archives (Taylor et al. 2012), but this possibly could be addressed in the future when COOKIE-like experiments are available in CMIP6 (Webb et al. 2017). Nevertheless, the results based on the idealized dry GCM shown in the previous subsection suggest that there should be a clear linear relationship between the amplitudes of the changes in ACRE, the upper-tropospheric meridional temperature gradient, and the poleward jet shift.

It should also be noted that the intermodel spread in the poleward jet shift in response to 4-K warming appears to be considerably larger when ACRE are turned off, which implies that noncloud radiative processes, such as the water vapor feedback (Voigt and Shaw 2015; Ceppi and Shepherd 2017) and surface albedo feedback (Ceppi and Shepherd 2017), may also play an important role in governing the intermodel spread in the response of the jet to global warming. Indeed, more spread in precipitation and circulation response in the tropics with warming are found when ACRE are off than when ACRE are on (Fläschner et al. 2018).

The results in Fig. 9 are shown for the zonal mean, which is reasonable in the SH but may miss important distinctions in the responses between the North Atlantic and North Pacific sectors in the NH. A more detailed analysis of the NH storm-track response to ACRE under climate change is deferred to a future study.

\section{Concluding remarks}

In this study, we examined the role of ACRE on the circulation response to climate change. To do so, we explored the differences in the circulation response to climate change in simulations run with and without ACRE in the COOKIE model intercomparison. We also used experiments run on an idealized dry GCM to explore the circulation response to ACRE-related thermal forcings. The key results are as follows:

- The magnitude of the poleward jet shift found in response to global warming of $4 \mathrm{~K}$ is substantially increased in simulations run with ACRE (Figs. 2c and 9), consistent with earlier findings that much of the jet shift under climate change is due to cloud radiative effects (Voigt and Shaw 2015, 2016; Ceppi and Hartmann 2016; Ceppi and Shepherd 2017). The results support the robustness of the importance of ACRE in the circulation response to climate change using a very different numerical framework (the COOKIE framework) than that used in those earlier studies.

- The enhanced poleward jet shift due to the inclusion of ACRE appears to derive primarily from the influence of ACRE on the upper-tropospheric meridional temperature gradient. The mechanism is summarized as follows: Surface warming leads to rising high clouds because of the thermodynamic constraint placed on the temperature of the tropopause in both the tropics (Hartmann and Larson 2002) and extratropics (Thompson et al. 2017). In turn, rising high clouds lead to enhanced ACRE in the upper troposphere and, because of the meridional slope of the tropopause, increases in the baroclinicity and a poleward shift of the jet. A similar mechanism appears to be at work in cloud-locking experiments (Voigt and Shaw 2015), which points to its robustness across different numerical setups.

- Experiments run with an idealized dry GCM simulation suggest that the radiative warming due to ACRE associated with rising high clouds plays a significant role in increasing the meridional temperature gradient in the upper troposphere and enhancing the poleward shift of the jet (Figs. 7c,d). The experiments also indicate a linear relationship between the amplitude of the ACRE and the jet shift: the larger the amplitude of the ACRE, the larger the increases in the tropopause height, the meridional temperature gradient in the upper troposphere, and the poleward shift of the jet (Fig. 8).

The key novel finding is the remarkable importance of rising high clouds for the extratropical circulation response to climate change not only in cloud-locking experiments (e.g., Voigt and Shaw 2016), but also in AMIP simulations such as those provided by the COOKIE experiment (this study). The tropopause lifts globally under climate change 
because of the thermodynamic constraints placed on clearsky radiative cooling by water vapor. And the resulting lifting of high clouds leads to changes in ACRE that project onto the latitude of the extratropical jet. When the resulting pattern of ACRE is applied as a heating in an idealized GCM, it leads to 1) increases in the uppertropospheric temperature gradient and 2) poleward shifts in the extratropical jet that vary linearly with the amplitude of the ACRE heating. The results suggest that the influence of ACRE on the extratropical jet shift may thus be viewed as an additional "robust" response of Earth's atmosphere to the physics conveyed in the ClausiusClapeyron relationship.

Acknowledgments. We thank the three anonymous referees for their thorough reviews and insightful comments, which have led to considerable improvements in this work. Y.L. is funded by NSF Climate and Large-Scale Dynamics (AGS-1547003) and NASA JPL Contract 1439268. D.W.J.T. is funded by NSF Climate and LargeScale Dynamics (AGS-1343080 and AGS-1547003). S.B. is funded by the European Research Council (ERC Grant 694768). T.M.M. is funded by Natural Sciences and Engineering Research Council (NSERC) Grant RGPIN-201405416 and acknowledges a Compute Canada allocation.

\section{APPENDIX}

\section{Exploring the Relative Importance of Climatological-Mean ACRE and Changes in ACRE on the Jet Response in a Dry GCM}

As mentioned in section $2 b$, differences in the circulation response to surface warming between simulations run with and without interactive ACRE in the COOKIE framework include two components: 1) the effects of the changes in ACRE that occur under climate change and 2) the effects of ACRE on the base-state climatological-mean circulation. These two components are unable to be separated in the standard COOKIE framework without running additional locking experiments. Here, we use the idealized dry GCM to provide some insights into the relative importance of the two components that are included in the COOKIE framework of the ACRE effects on the circulation responses to global warming, although the direct comparison is not possible.

First we run the three simulations forced with different ACRE forcings (A0, A1, and A2) applied to the base climatology in the control Held-Suarez state (T1):

- T1A0 is forced with the Held-Suarez base state (T1) and no ACRE forcing (A0) (Fig. A1a).
- T1A1 is forced with the Held-Suarez base state (T1) and the forcing due to ACRE in the control simulation (A1; shown in Fig. 4c of Li et al. 2015)(Fig. A1d).

- T1A2 is forced with the Held-Suarez base state (T1) and the forcing due to ACRE in the 4-K simulation (A2) (Fig. A1g). Note that the forcing A2 is equal to the sum of $\mathrm{A} 1$ and the heating shown here in Fig. $4 \mathrm{~b}$.

The climatological-mean zonal flow for these simulations is shown in the left column of Fig. A1 (Figs. Ala,d,g).

We then run three simulations forced with same above ACRE forcings (A0, A1, and A2), but on top of the base climatology derived from the global warming state (T2). The global warming state is defined as the Held-Suarez climatology forced with the tropical heating used in Butler et al. (2010, see their Fig. 2a), which mimics the meridional structure of the global warming response in the free atmosphere. The results are shown in the center column of Fig. A1:

- $\mathrm{T} 2 \mathrm{~A} 0$ is run with the tropical heating superposed on the basic state given by the T1A0 simulation (Fig. A1b).

- T2A1 is run with the tropical heating superposed on the basic state given by the T1A1 simulation (Fig. A1e).

- T2A2 is run with the tropical heating superposed on the basic state given by the T1A2 simulation (Fig. A1h).

The terms [T1A2-T1A1] and [T2A2-T2A1] are shown in the bottom row of Fig. A1, and indicate the effect of the changes in ACRE from A1 to A2 on the circulation when it is applied to the T1A1 and T2A1 climatologies, respectively (Figs. A1j,k). The average $(1 / 2)[(\mathrm{T} 1 \mathrm{~A} 2-\mathrm{T} 1 \mathrm{~A} 1)+(\mathrm{T} 2 \mathrm{~A} 2-\mathrm{T} 2 \mathrm{~A} 1)]$ is shown in Fig. A2a, and indicates the effect of warming-induced changes in ACRE on the circulation response. The spatial patterns of the temperature and zonal wind responses in Fig. A2a are very similar to those in Fig. 7c. The slight differences are due to the different mean position of the jet in the base state (T1A0 versus T1A1) that the thermal forcing is applied to.

The differences [T2A 0 - T1A0], [T2A1 - T1A1], and [T2A2 - T1A2] are shown in the right column of Fig. A1, and indicate the effects of tropical heating on the circulation when it is applied to the T1A0, T1A1, and T1A2 climatologies, respectively (Figs. A1c,f,i). The term $(1 / 2)[(\mathrm{T} 2 \mathrm{~A} 2-\mathrm{T} 1 \mathrm{~A} 2)+(\mathrm{T} 2 \mathrm{~A} 1-\mathrm{T} 1 \mathrm{~A} 1)]-(\mathrm{T} 2 \mathrm{~A} 0-$ T1A0) is shown in Fig. A2b, and indicates the effects of the changes in the base state due to the inclusion of climatological ACRE on the circulation response to global warming. The inclusion of climatological ACRE shifts the mean jet position by $\sim 15^{\circ}$ in the idealized dry GCM (as inferred from the differences between T1A1 and $\mathrm{T} 1 \mathrm{~A} 0$ in Figs. A1d and A1a), but only $\sim 1^{\circ}-2^{\circ}$ in the IPSL model (as inferred from the jet position on the solid 
a) $\mathrm{T} 1 \mathrm{AO}$
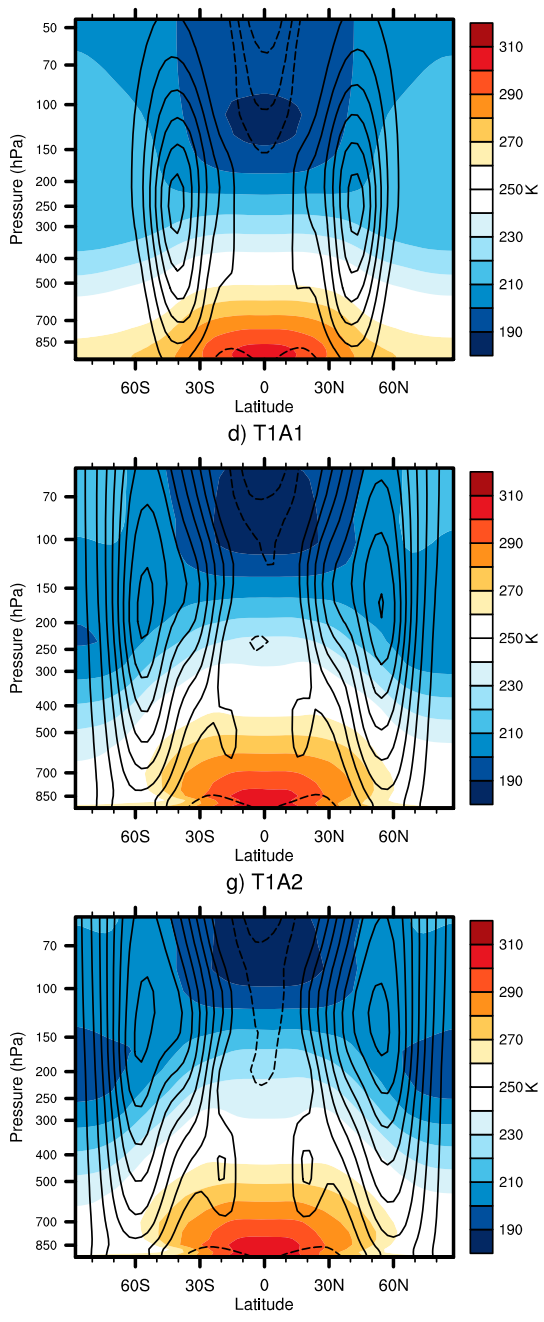

j) effect of $A 1->A 2$ forcing (T1A2-T1A1)

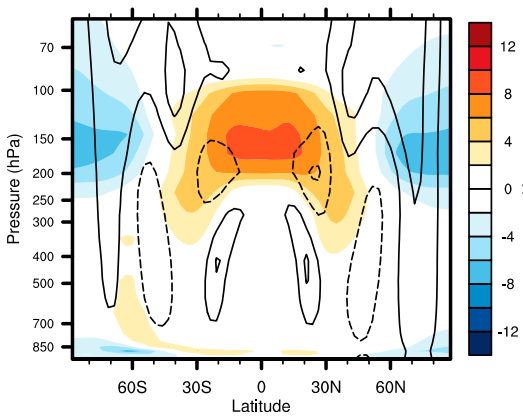

b) $\mathrm{T} 2 \mathrm{AO}$
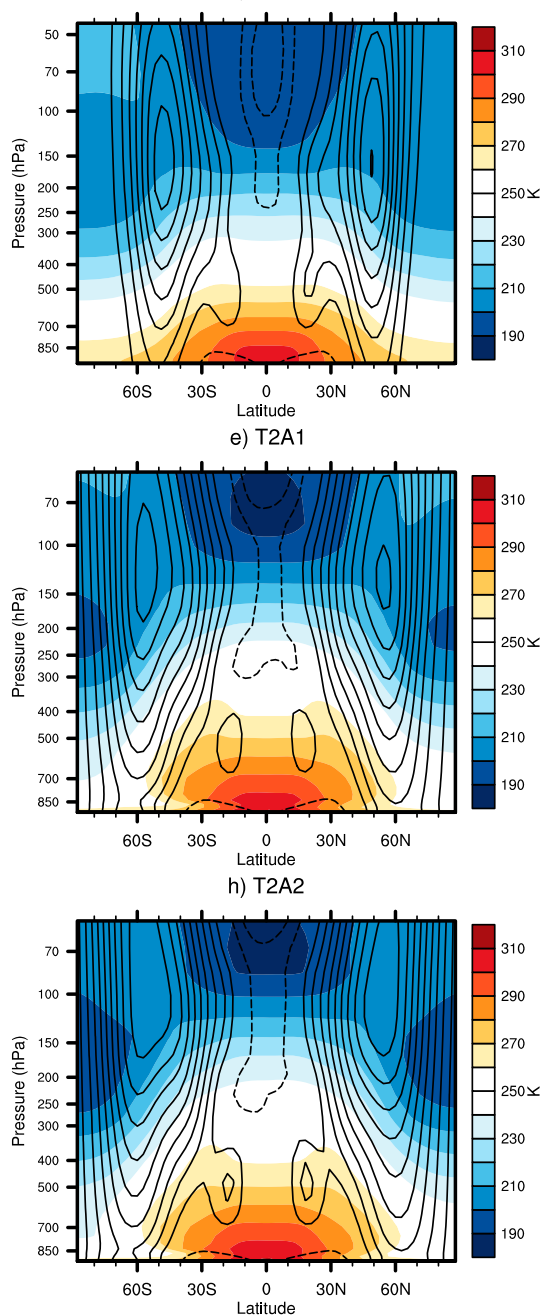

k) effect of A1->A2 forcing (T2A2-T2A1)

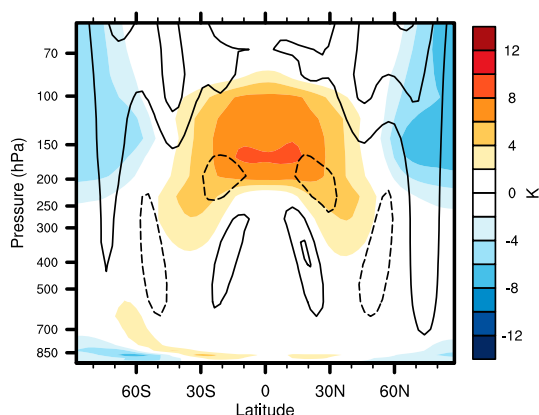

c) effect of $\mathrm{T} 1->\mathrm{T} 2$ forcing (T2A0-T1 A0)
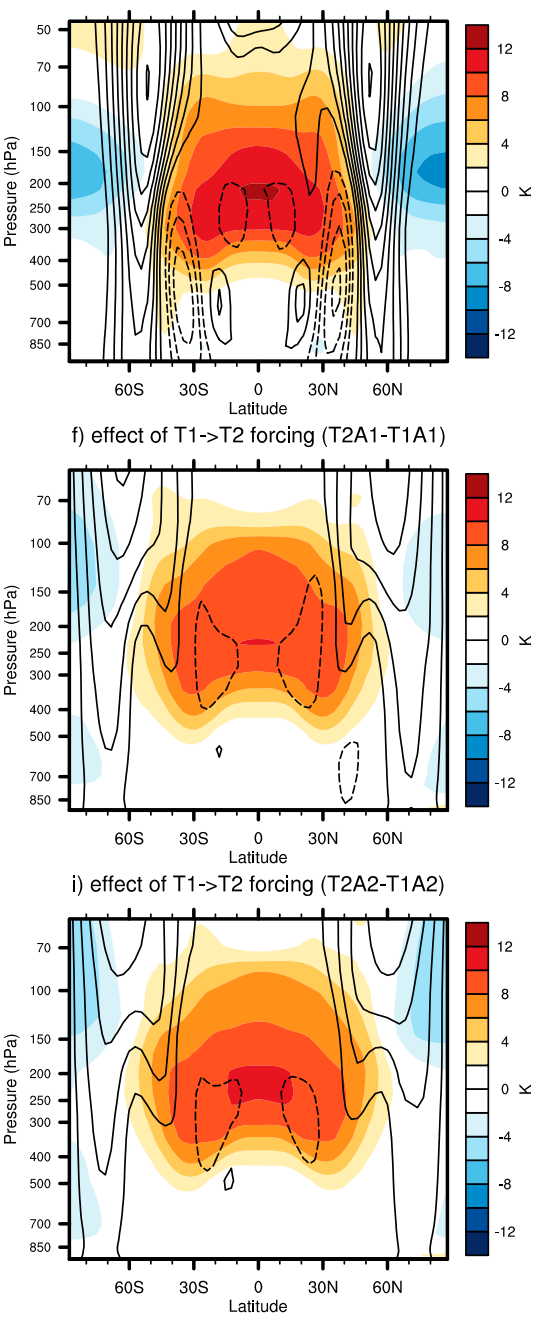

FIG. A1. (a),(b),(d),(e),(g),(h) Zonal-mean temperature (shading) and zonal-mean zonal wind (contours; contour interval: 5 m s ${ }^{-1}$ ) for the simulations forced with six different combinations of thermal forcing (T1, T2) and ACRE forcing (A0, A1, A2) as described in the appendix. (c),(f),(i),(j),(k) Changes in zonal-mean temperature (shading) and zonal-mean zonal wind (contours; contour interval: $2.5 \mathrm{~m} \mathrm{~s}^{-1}$ ): (c) is the difference between (b) and (a), (f) is the difference between (e) and (d), (i) is the difference between (h) and ( $\mathrm{g}$ ), (j) is the difference between $(\mathrm{g})$ and $(\mathrm{d})$, and $(\mathrm{k})$ is the difference between $(\mathrm{h})$ and $(\mathrm{e})$.

diagonal line in Fig. 9). As such, this component of the ACRE effect on the jet shift to global warming estimated is likely overestimated in the dry GCM relative to the COOKIE simulation.
The simulations run with the idealized dry GCM highlight the nonlinear nature of the jet response to climate change. They also highlight the importance of considering the effects of ACRE on both the base state 

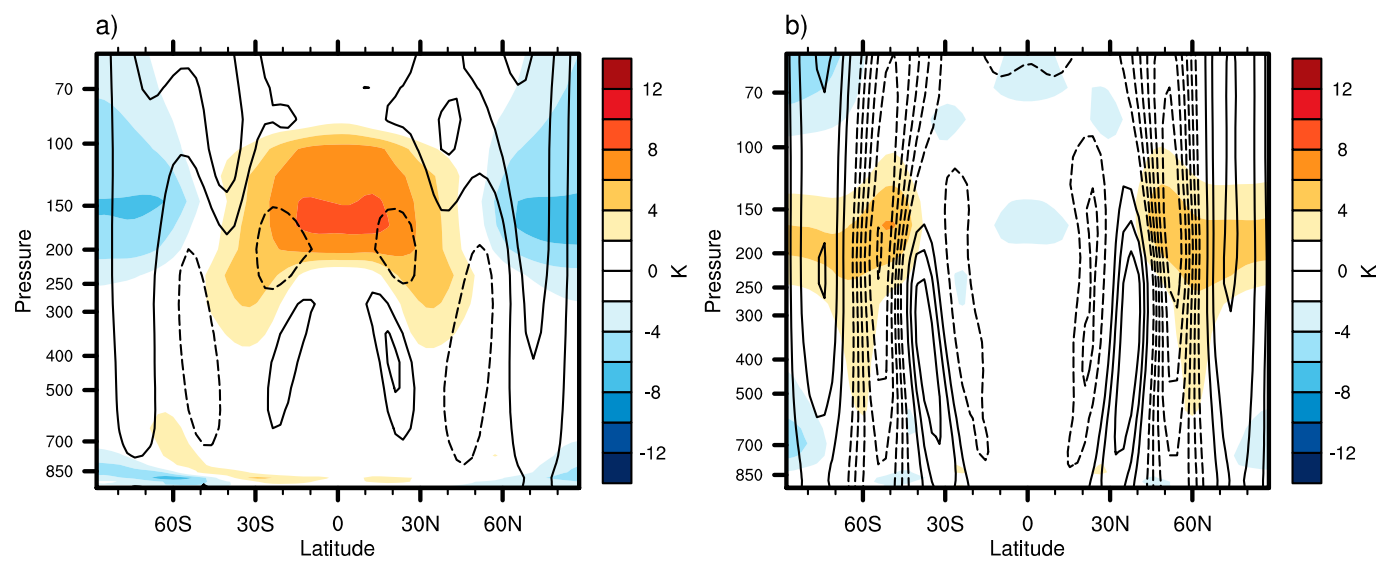

FIG. A2. The responses in zonal-mean temperature (shading) and zonal-mean zonal wind (contours; contour interval: $2.5 \mathrm{~m} \mathrm{~s}^{-1}$ ) for (a) the component due to the effects of changes in ACRE that occur under climate changes on the circulation response to global warming $\{(1 / 2)[(\mathrm{T} 2 \mathrm{~A} 2-\mathrm{T} 2 \mathrm{~A} 1)+(\mathrm{T} 1 \mathrm{~A} 2-\mathrm{T} 1 \mathrm{~A} 1)]\}$, and (b) the component due to the effects of ACRE on base-state climatological-mean circulation which, in turn, influences the circulation response to warming $\{(1 / 2)[(\mathrm{T} 2 \mathrm{~A} 2-\mathrm{T} 1 \mathrm{~A} 2)+(\mathrm{T} 2 \mathrm{~A} 1-\mathrm{T} 1 \mathrm{~A} 1)]-(\mathrm{T} 2 \mathrm{~A} 0-\mathrm{T} 1 \mathrm{~A} 0)\}$.

and the net heating in climate change simulations. However, they are not quantitatively comparable to the COOKIE simulations for several reasons, notably 1) the dry model "ACRE" are imposed as a thermal forcing and are not coupled to the circulation, 2) the dry model "climate change forcing" is given as a simple heating profile focusing on the tropical warming without considering, say, the stratospheric cooling or polar low-level warming, 3) the dry model has no topography or seasonal cycle, whereas the extratropical circulation responses can be seasonally and latitudinally varying (Simpson et al. 2014), and 4) the meridional shift of the circulation in the dry GCM is sensitive not only to the base-state climatology but also the meridional scale of the tropical thermal forcing (Tandon et al. 2013; Sun et al. 2013).

\section{REFERENCES}

Barnes, E. A., and D. L. Hartmann, 2010: Dynamical feedbacks and the persistence of the NAO. J. Atmos. Sci., 67, 851-865, https://doi.org/10.1175/2009JAS3193.1.

_ , and L. M. Polvani, 2013: Response of the midlatitude jets and of their variability to increased greenhouse gases in the CMIP5 model. J. Climate, 26, 7117-7135, https://doi.org/ 10.1175/JCLI-D-12-00536.1.

Bony, S., G. Bellon, D. Klocke, S. Sherwood, S. Fermepin, and S. Denvil, 2013: Robust direct effect of carbon dioxide on tropical circulation and regional precipitation. Nat. Geosci., 6 , 447-451, https://doi.org/10.1038/ngeo1799.

- B. Stevens, D. Coppin, T. Becker, K. A. Reed, A. Voigt, and B. Medeiros, 2016: Thermodynamic control of anvil cloud amount. Proc. Natl. Acad. Sci. USA, 113, 8927-8932, https:// doi.org/10.1073/pnas.1601472113.

Butler, A. H., D. Thompson, and R. Heikes, 2010: The steady-state atmospheric circulation response to climate change-like thermal forcings in a simple general circulation model. J. Climate, $\mathbf{2 3}$, 3474-3496, https://doi.org/10.1175/2010JCLI3228.1.

Ceppi, P., and D. L. Hartmann, 2016: Clouds and the atmospheric circulation response to warming. J. Climate, 29, 783-799, https://doi.org/10.1175/JCLI-D-15-0394.1.

_ , and T. G. Shepherd, 2017: Contributions of climate feedbacks to changes in atmospheric circulation. J. Climate, 30, $9097-$ 9118, https://doi.org/10.1175/JCLI-D-17-0189.1.

— , Y.-T. Hwang, D. M. W. Frierson, and D. L. Hartmann, 2012: Southern Hemisphere jet latitude biases in CMIP5 models linked to shortwave cloud forcing. Geophys. Res. Lett., 39 , L19708, https://doi.org/10.1029/2012GL053115.

— M. D. Zelinka, and D. L. Hartmann, 2014: The response of the Southern Hemispheric eddy-driven jet to future changes in shortwave radiation in CMIP5. Geophys. Res. Lett., 41, 32443250, https://doi.org/10.1002/2014GL060043.

Chen, G., and I. M. Held, 2007: Phase speed spectra and the recent poleward shift of Southern Hemisphere surface westerlies. Geophys. Res. Lett., 34, L21805, https://doi.org/10.1029/2007GL031200.

- J. Lu, and D. Frierson, 2008: Phase speed spectra and the latitude of surface westerlies: Interannual variability and global warming trend. J. Climate, 21, 5942-5959, https://doi.org/ 10.1175/2008JCLI2306.1.

Collins, W., and Coauthors, 2008: Evaluation of HadGEM2 model. Hadley Centre Tech. Note 74, 47 pp.

Deser, C., and A. S. Phillips, 2009: Atmospheric circulation trends, 1950-2000: The relative roles of sea surface temperature forcing and direct atmospheric radiative forcing. J. Climate, 22, 396-413, https://doi.org/10.1175/2008JCLI2453.1.

Dufresne, J.-L., and Coauthors, 2013: Climate change projections using the IPSL-CM5 Earth system model: From CMIP3 to CMIP5. Climate Dyn., 40, 2123-2165, https://doi.org/10.1007/ s00382-012-1636-1.

Fermepin, S., and S. Bony, 2014: Influence of low-cloud radiative effects on tropical circulation and precipitation. J. Adv. Model. Earth Syst., 6, 513-526, https://doi.org/10.1002/2013MS000288.

Fläschner, D., T. Mauritsen, B. Stevens, and S. Bony, 2018: The signature of shallow circulations, not cloud radiative effects, in the spatial distribution of tropical precipitation. J. Climate, $\mathbf{3 1}$, 9489-9505, https://doi.org/10.1175/JCLI-D-18-0230.1. 
Frierson, D., 2008: Midlatitude static stability in simple and comprehensive general circulation models. J. Atmos. Sci., 65, 1049-1062, https://doi.org/10.1175/2007JAS2373.1.

Grise, K. M., and L. M. Polvani, 2014: Southern Hemisphere cloud-dynamics biases in CMIP5 models and their implications for climate projections. J. Climate, 27, 6074-6092, https:// doi.org/10.1175/JCLI-D-14-00113.1.

—_, and _ 2017: Understanding the time scales of the tropospheric circulation response to abrupt $\mathrm{CO}_{2}$ forcing in the Southern Hemisphere: Seasonality and the role of the stratosphere. J. Climate, 30, 8497-8515, https://doi.org/10.1175/ JCLI-D-16-0849.1.

Hall, N. M. J., B. J. Hoskins, P. J. Valdes, and C. A. Senior, 1994: Storm tracks in a high-resolution GCM with doubled carbon dioxide. Quart. J. Roy. Meteor. Soc., 120, 1209-1230, https:// doi.org/10.1002/qj.49712051905.

Hartmann, D. L., and K. Larson, 2002: An important constraint on tropical cloud-climate feedback. Geophys. Res. Lett., 29, 1951, https://doi.org/10.1029/2002GL015835.

Held, I. M., and M. J. Suarez, 1994: A proposal for the intercomparison of the dynamical cores of atmospheric general circulation models. Bull. Amer. Meteor. Soc., 75, 1825-1830, https://doi.org/10.1175/ 1520-0477(1994)075<1825:APFTIO>2.0.CO;2.

Hourdin, F., and Coauthors, 2013a: Impact of the LMDZ atmospheric grid configuration on the climate and sensitivity of the IPSL-CM5A coupled model. Climate Dyn., 40, 2167-2192, https://doi.org/10.1007/s00382-012-1411-3.

_ - and Coauthors, 2013b: LMDZ5B: The atmospheric component of the IPSL climate model with revisited parameterizations for clouds and convection. Climate Dyn., 40, 2193-2222, https://doi.org/10.1007/s00382-012-1343-y.

Kidston, J., and E. P. Gerber, 2010: Intermodel variability of the poleward shift of the austral jet stream in the CMIP3 integrations linked to biases in 20th century climatology. Geophys. Res. Lett., 37, L09708, https://doi.org/10.1029/ 2010 GL042873.

Kuang, Z., and D. L. Hartmann, 2007: Testing the fixed anvil temperature hypothesis in a cloud-resolving model. J. Climate, 20, 2051-2057, https://doi.org/10.1175/JCLI4124.1.

Kushner, P. J., I. M. Held, and T. L. Delworth, 2001: Southern Hemisphere atmospheric circulation response to global warming. J. Climate, 14, 2238-2249, https://doi.org/10.1175/ 1520-0442(2001)014<0001:SHACRT $>2.0$. CO;2.

Li, Y., D. W. J. Thompson, and S. Bony, 2015: The influence of atmospheric cloud radiative effects on the large-scale atmospheric circulation. J. Climate, 28, 7263-7278, https://doi.org/ 10.1175/JCLI-D-14-00825.1.

- -, and Y. Huang, 2017: The influence of atmospheric cloud radiative effects on the large-scale stratospheric circulation. J. Climate, 30, 5621-5635, https://doi.org/10.1175/JCLID-16-0643.1.

Lorenz, D. J., 2014: Understanding midlatitude jet variability and change using Rossby wave chromatography: Poleward-shifted jets in response to external forcing. J. Atmos. Sci., 71, 23702389, https://doi.org/10.1175/JAS-D-13-0200.1.

—_, and E. T. DeWeaver, 2007: Tropopause height and zonalwind response to global warming in the IPCC scenario integrations. J. Geophys. Res., 112, D10119, https://doi.org/ 10.1029/2006JD008087.

Polvani, L. M., and P. Kushner, 2002: Tropospheric response to stratospheric perturbations in a relatively simple general circulation model. Geophys. Res. Lett., 29, 1114, https://doi.org/ 10.1029/2001GL014284.
Popke, D., B. Stevens, and A. Voigt, 2013: Climate and climate change in a radiative-convective equilibrium version of ECHAM6. J. Adv. Model. Earth Syst., 5, 1-14, https://doi.org/ 10.1029/2012MS000191.

Santer, B. D., and Coauthors, 2003: Contributions of anthropogenic and natural forcing to recent tropopause height changes. Science, 301, 479-483, https://doi.org/10.1126/science.1084123.

Sherwood, S. C., S. Bony, O. Boucher, C. Bretherton, P. M. Forster, J. M. Gregory, and B. Stevens, 2015: Adjustments in the forcing-feedback framework for understanding climate change. Bull. Amer. Meteor. Soc., 96, 217-228, https://doi.org/10.1175/ BAMS-D-13-00167.1.

Simpson, I. R., and L. M. Polvani, 2016: Revisiting the relationship between jet position, forced response, and annular mode variability in the southern midlatitudes. Geophys. Res. Lett., 43, 2896-2903, https://doi.org/10.1002/2016GL067989.

_ T. A. Shaw, and R. Seager, 2014: A diagnosis of the seasonally and longitudinally varying midlatitude circulation response to global warming. J. Atmos. Sci., 71, 2489-2515, https://doi.org/10.1175/JAS-D-13-0325.1.

Singh, M., and P. O'Gorman, 2012: Upward shift of the atmospheric general circulation under global warming: Theory and simulations. J. Climate, 25, 8259-8276, https://doi.org/10.1175/ JCLI-D-11-00699.1.

Stevens, B., and S. Bony, 2013: What are climate models missing? Science, 340, 1053-1054, https://doi.org/10.1126/science.1237554.

_ - _ and M. Webb, 2012: Clouds On-Off Klimate Intercomparison Experiment (COOKIE). 12 pp., http://www. euclipse.eu/downloads/Cookie.pdf.

Sun, L., G. Chen, and J. Lu, 2013: Sensitivities and mechanisms of the zonal mean atmospheric circulation response to tropical warming. J. Atmos. Sci., 70, 2487-2504, https://doi.org/10.1175/ JAS-D-12-0298.1.

Tandon, N. F., E. P. Gerber, A. H. Sobel, and L. M. Polvani, 2013: Understanding Hadley cell expansion versus contraction: Insights from simplified models and implications for recent observations. J. Climate, 26, 4304-4321, https://doi.org/10.1175/ JCLI-D-12-00598.1.

Taylor, K. E., R. J. Stouffer, and G. A. Meehl, 2012: An overview of CMIP5 and the experiment design. Bull. Amer. Meteor. Soc., 93, 485-498, https://doi.org/10.1175/BAMS-D-11-00094.1.

Thompson, D. W. J., S. Bony, and Y. Li, 2017: Thermodynamic constraint on the depth of the global tropospheric circulation. Proc. Natl. Acad. Sci. USA, 114, 8181-8186, https://doi.org/ 10.1073/pnas.1620493114.

Vallis, G., P. Zurita-Gotor, C. Cairns, and J. Kidston, 2015: Response of the large-scale structure of the atmosphere to global warming. Quart. J. Roy. Meteor. Soc., 141, 1479-1501, https:// doi.org/10.1002/qj.2456.

Voigt, A., and T. A. Shaw, 2015: Radiative changes of clouds and water vapor shape circulation response to global warming. Nat. Geosci., 8, 102-106, https://doi.org/10.1038/ngeo2345.

- and - 2016: Impact of regional atmospheric cloud radiative changes on shifts of the extratropical jet stream in response to global warming. J. Climate, 29, 8399-8421, https:// doi.org/10.1175/JCLI-D-16-0140.1.

Voldoire, A., and Coauthors, 2013: The CNRM-CM5.1 global climate model: Description and basic evaluation. Climate Dyn., 40, 2091-2121, https://doi.org/10.1007/s00382-011-1259-y.

Watt-Meyer, O., and D. M. W. Frierson, 2017: Local and remote impacts of atmospheric cloud radiative effects onto the eddydriven jet. Geophys. Res. Lett., 44, 10 036-10044, https://doi.org/ 10.1002/2017GL074901. 
Webb, M. J., and Coauthors, 2017: The Cloud Feedback Model Intercomparison Project (CFMIP) contribution to CMIP6. Geosci. Model Dev., 10, 359-384, https://doi.org/10.5194/ gmd-10-359-2017.

Yin, J. H., 2005: A consistent poleward shift of the storm tracks in simulations of 21st century climate. Geophys. Res. Lett., 32, L18701, https://doi.org/10.1029/2005GL023684.

Yukimoto, S., and Coauthors, 2012: A new global climate model of the Meteorological Research Institute: MRI-CGCM3-Model description and basic performance. J. Meteor. Soc. Japan, $\mathbf{9 0 A}$, 23-64, https://doi.org/10.2151/jmsj.2012-A02.

Zelinka, M. D., and D. L. Hartmann, 2010: Why is longwave cloud feedback positive? J. Geophys. Res., 115, D16117, https:// doi.org/10.1029/2010JD013817.

S. Klein, K. Taylor, T. Andrews, M. Webb, J. Gregory, and P. Forster, 2013: Contributions of different cloud types to feedbacks and rapid adjustments in CMIP5. J. Climate, 26, 5007-5027, https://doi.org/10.1175/JCLI-D-12-00555.1. 